\title{
PICK1-mediated GluR2 endocytosis contributes to cellular injury after neuronal trauma
}

\author{
JD Bell ${ }^{1,2}$, Park$^{1}, \mathrm{~J} \mathrm{Ai}^{3}$ and AJ Baker, ${ }^{*, 1,2,4}$
}

Constitutive and activity-dependent regulation of the AMPA receptor GluR2 content is recognized as an important mediator of both neuronal plasticity and vulnerability to excitotoxic neuron death. In the latter case, inclusion of GluR2 protects against glutamate excitotoxicity in CNS disease by lowering receptor single-channel conductance and preventing deleterious calcium influx. We investigated the hypothesis that aberrations in GluR2 trafficking after in vitro and in vivo cerebral trauma contribute to excitotoxicity and associated calcium-dependent cell death processes. First, in an in vitro model of traumatic brain injury (TBI), we observed PICK1 and $\mathrm{N}$-methyl-D-aspartic acid (NMDA) receptor-dependent phosphorylation and internalization of GluR2. The contributing cell signaling mechanisms involved enhanced binding between PKC $\alpha$ (the kinase that phosphorylates GluR2) and PICK1 (its PDZ-binding partner), and a novel protein interaction between PKC $\alpha$ and the NMDA receptor scaffolding protein PSD95. Functionally, these phenomena enhanced single cell AMPAR mEPSCs and protracted calcium extrusion. In vivo TBI similarly promoted GluR2 phosphorylation and internalization, with enhanced expression of calcium-permeable AMPARs in the injured hippocampus. Peptide-mediated perturbation of the PKC $\alpha /$ PICK1 protein interaction after trauma preserved surface GluR2 expression, attenuated AMPAR-mediated toxicity, and occluded the sensitivity of neuronal physiology to calcium-permeable AMPAR antagonists. These findings suggest that experimental TBI promotes the expression of injurious GluR2-lacking AMPARs, thereby enhancing cellular vulnerability to secondary excitotoxicity.

Cell Death and Differentiation (2009) 16, 1665-1680; doi:10.1038/cdd.2009.106; published online 31 July 2009

Traumatic brain injury (TBI) continues to be a leading cause of morbidity and disability in North America. ${ }^{1}$ At the cellular level, excitotoxic stimulation of $N$-methyl-D-aspartate (NMDA) and $\alpha$-amino-3-hydroxy-5-methyl-4-isoxazolepropionic acid (AMPA) glutamatergic receptors has a major function in the deregulation of calcium homeostasis and acute cell swelling after TBI, ultimately leading to secondary neuronal cell death hours to days after the primary injury. ${ }^{1}$ Unfortunately, global antagonism of these ionotropic channels (which has generally targeted the highly calciumpermeable NMDARs) is a clinically impractical approach because of interference with physiological receptor function. $^{2}$ As such, it remains of critical importance to identify novel potential intracellular targets of anti-excitotoxic therapy to mitigate delayed secondary cell loss, and improve functional outcome after TBI.

Physiologically, AMPA receptors mediate the majority of excitatory ionotropic neurotransmission in the CNS. ${ }^{3}$ Pathologically, however, AMPA receptors can also mediate excitotoxic neuronal damage when GluR2 subunits are absent from the tetrameric receptor complex ${ }^{4}$ (composed of four subunits, GluR1-4). This is because receptors devoid of the GluR2 subunit (e.g. homomers of GluR1) exhibit two- to three-fold increases in single-channel conductance, increased calcium and zinc permeability and have inwardly rectifying current-voltage relationships. ${ }^{5}$ These attributes increase synaptic strength, but are also known to exacerbate neuronal hyperactivity, acute cell swelling and delayed $\mathrm{Ca}^{2+}$-mediated toxicity in CNS pathologies including ischemia, $^{6,7}$ epilepsy $^{8}$ and trauma. ${ }^{9,10}$ Investigation into the intracellular regulation of the AMPAR GluR2 content under pathological conditions is therefore warranted, and may help in the design of targeted therapeutics aimed at reducing delayed $\mathrm{Ca}^{2+}$ overload or neuronal hyperexcitability after an initial trauma.

The sub-cellular mechanisms of physiological GluR2 trafficking are well described in the literature. During GluR2 endocytosis, calcium-activated protein kinase $\mathrm{C} \alpha(\mathrm{PKC} \alpha)$ is trafficked to the plasma membrane from its constitutively cytosolic location by protein interacting with $C$ kinase 1 (PICK1). ${ }^{11}$ Once bound to PICK1, PKC $\alpha$ then phosphorylates GluR2 at serine residue $880,{ }^{12,13}$ conferring the association of GluR2 with PICK1, and subsequent subunit endocytosis. The net effect of GluR2 reduction is frequently an increased

\footnotetext{
${ }^{1}$ Cara Phelan Centre for Trauma Research and Keenan Research Centre in the Li Ka Shing Knowledge Institute, St. Michael's Hospital, Toronto, Ontario, Canada; ${ }^{2}$ Faculty of Medicine, Institute of Medical Science, University of Toronto, Toronto, Ontario, Canada; ${ }^{3}$ Division of Neurosurgery, St. Michael's Hospital, Toronto, Ontario, Canada and ${ }^{4}$ Departments of Critical Care and Anesthesia, St. Michael's Hospital, Toronto, Ontario, Canada

${ }^{*}$ Corresponding author: AJ Baker, Anaesthesia and Trauma Research, St. Michael's Hospital, 30 Bond St., 7th floor Bond Wing, Rm 088, Toronto, Ontario, Canada M5B1W8. Tel: + 1416864 5559; Fax: + 14168646013 12; E-mail: bakera@smh.toronto.on.ca

Keywords: AMPA; PICK1; trauma; GluR2; stretch; PKC $\alpha$

Abbreviations: AMPA, alpha-amino-3-hydroxy-5-methyl-4-isoxazolepropionic acid; PICK1, protein interacting with C kinase 1; GluR2, glutamate receptor subunit 2; NMDA, $N$-methyl-D-aspartic acid; p.s.i, pounds per square inch; LTD/LTP, long-term depression/potentiation; naspm, 1 naphthyl-acetyl spermine; mEPSC, miniature excitatory post-synaptic current; PKC $\alpha$, protein kinase $\mathrm{C} \alpha$; HBSS, Hank's balanced salt solution; D-MEM, Dulbecco's modified eagle medium; PBS, phosphate buffered saline; PSD-95, post-synaptic density protein, $95 \mathrm{kDa}$; PDZ, post-synaptic density protein (PSD95); DlgA, drosophila disc large tumor suppressor; zo-1, zonula occludens-1 protein; TBI, traumatic brain injury

Received 12.2.09; revised 22.6.09; accepted 26.6.09; Edited by L Greene; published online 31.7.09
} 
population of calcium-permeable AMPA receptors, ${ }^{14,15}$ a condition that might place neurons at risk for subsequent excitotoxic deterioration if the process is unregulated. This study investigates this hypothesis in the context of acute neuronal trauma.

Here, we show that after in vitro cortical trauma surface GluR2 is internalized through an NR2b and PICK1-dependent mechanism. The reduced surface GluR2 expression after traumatic injury imparted ionic conductances characteristic of calcium-permeable AMPA receptors, and as such increased cellular vulnerability to secondary excitotoxicity. Similarly, in vivo $\mathrm{TBI}$ (fluid percussion trauma) also promoted GluR2 endocytotic signaling, attenuated by treatment with a novel PICK1 inhibitory peptide. We therefore suggest that PICK1mediated GluR2 endocytosis imparts neuronal vulnerability to secondary injury after modeled TBI.

\section{Results}

In vitro TBI (stretch + NMDA) increases $\mathbf{5 8 0}$ phosphorylation of GluR2 and vulnerability to secondary AMPA toxicity. GluR2 endocytosis is preceded by PKC $\alpha$ dependent serine 880 phosphorylation. ${ }^{16,17}$ We examined this protein modification and its role in delayed cell death in our earlier established model of sublethal mechanical trauma followed by mild excitotoxicity (see Figure 1a). Relative to control cultures, stretch injury alone or application of $10 \mu \mathrm{M}$ NMDA for $1 \mathrm{~h}$ had no significant effects on GluR2 phosphorylation (GluR2 phosphorylation $=109 \pm 2.3 \%$ of control, $P=0.12$ for $10 \mu \mathrm{M}$ NMDA versus control; GluR2 phosphorylation $=91 \pm 8.3 \%$ of control, $P=0.16$ for stretch versus control, Figure $1 \mathrm{~b}$ and $\mathrm{c}$ ). However, stretch coupled with NMDA receptor stimulation synergistically increased GluR2 phosphorylation (GluR2 phosphorylation $=164 \pm$ $10.3 \%$ of control, $P<0.01$, Figure $1 \mathrm{~b}$ and $\mathrm{c}$, but see also quantification in Figure 2f). Subsequently, stretch + NMDA insult also resulted in an increased vulnerability of cortical cells to a challenge of $30 \mu \mathrm{M}$ AMPA $(24.98 \pm 4.8 \%$ increase in cell death, $P<0.05$, Figure $1 \mathrm{~d}$ and $\mathrm{e})$. Conditions that did not enhance the expression of phosphorylated GluR2 did not result in delayed cell death after exposure to AMPA challenge (stretch + AMPA $=0.97 \pm 2.8 \%$ increase in cell death; NMDA + AMPA $=5.7 \pm 2.5 \%, P>0.05$, Figure 1d). Stretch + NMDA without a secondary AMPA treatment did not result in an increase in delayed cell death $(4.12 \pm$ $1.4 \%$ increase, $P>0.05)$. Representative micrographs of propidium iodide (PI) uptake are presented in Figure 1d. Collectively, these initial results suggested that stretch injury coupled with NMDAR stimulation resulting in GluR2 phos- phorylation conferred heightened sensitivity to excitotoxic challenge of a dose of AMPA that remained innocuous in normal conditions.

Significant differences in GluR2 phosphorylation were also detected among treatment groups $(P<0.001, F=26.197)$. Post hoc analysis showed attenuation of GluR2 phosphorylation by selective antagonism of NR2b-containing NMDA receptors $(32.7 \pm 6.1 \%$ of control, $P<0.001$, Figure $1 f)$, whereas antagonism of NR2A-containing NMDARs was ineffective (Figure 1g). Data for GluR2 phosphorylation are quantified in Figure $2 f$.

Stretch + NMDA promotes binding of GluR2 endocytotic proteins. We next incubated cultures with a 15 amino-acid transacting activator of transcription. (TAT) peptide (TAT-QSAV) that mimics the extreme c-terminus PDZbinding motif of $P K C \alpha$, thereby designed to inhibit the $\mathrm{PICK} 1-\mathrm{PKC} \alpha$ protein interaction. After confirming successful transduction of the peptide (Figure 2a), we examined the effects of TAT-QSAV on the protein interaction between $\mathrm{PKC} \alpha$ and PICK1 in the in vitro injury paradigm. Stretch + NMDA significantly augmented PKC $\alpha-$ PICK1 binding (169 $\pm 5.6 \%$ of control; $P<0.01$, Figure $2 b)$, an effect attenuated by NR2b antagonism $(65.6 \pm 9.6 \%$ of control levels, $P<0.01$, Figure 2b) and TAT-QSAV $(68.3 \pm 16.7 \%$ of control, $P<0.01)$. TAT-AAAA (a control peptide) was ineffective $(162.9 \pm 6.5 \%$ of control, $2 \mathrm{~b}$ and $4 \mathrm{f})$. Data are quantified in Figure 2c. TAT-QSAV, but not TATAAAA, also interfered with trauma-induced phosphorylation of GluR2 (respectively, $90.5 \pm 18.3 \%$ of control, $P<0.05$, versus $161.8 \pm 11.1 \%$ of control, $P=0.43$ versus stretch + NMDA, Figure 2d). Total GluR2 protein expression did not differ in any of the treatment conditions $(P=0.67$, Figure 2e). Data of total and phosphorylated GluR2 are quantified in Figure $2 f$.

It is known that $\mathrm{PKC} \alpha$ activation increases its binding with $\mathrm{PICK} 1^{10}$ and that $\mathrm{PKC} \alpha$ activation can occur endogenously through binding of intracellular calcium. ${ }^{18}$ Given the NR2b dependence of the PKC $\alpha / P I C K 1$ increase, we attempted to co-precipitate $\mathrm{PKC} \alpha$ with PSD-95, the NR2b-connected scaffolding protein that links incoming NMDAR-derived calcium to substrates embedded in the protein complex. We first observed co-immunoprecipitation of PSD-95 with PKC $\alpha$ (Figure $2 \mathrm{~g}$ and $\mathrm{h}$ ), with PICK1 pull-down, whole-cell lysates and bound nNOS (a known binding partner of PSD-95) as positive controls (Figure $2 \mathrm{~h}$ ). Subsequently, we observed that the PKC $\alpha-P S D-95$ interaction was also markedly increased after strech + NMDA (168 $\pm 30.3 \%$ of control levels, $P<0.05$, Figure $2 \mathrm{i}$ and $\mathrm{j})$. Both NR2b antagonism $(74 \pm 28.1 \%$ of

\footnotetext{
Figure 1 Stretch + NMDA increases S880 phosphorylation of GluR2 and vulnerability to secondary AMPA toxicity. (a) Schematic of in vitro trauma model. Mechanical strain injury is coupled with mild secondary excitotoxicity to mimic biomechanical and biochemical loading placed on injured neurons after TBI. (b) Western blot of GluR2 phosphorylation at c-terminus serine residue 880. Stretch + NMDA (but neither condition alone) markedly increased phosphorylation. Membranes were stripped and re-probed for $\beta$-actin as a loading control. (c) Data represented in (b), quantified as integrated optical density (IOD) normalized to control values, which are assumed to represent $100 \%$ expression. (d) Representative micrographs of propidium iodide (PI) fluorimetry after stretch + AMPA, NMDA + AMPA, stretch + NMDA or stretch + NMDA + AMPA. Scale bars $=75 \mu \mathrm{m}$. (e) Plate scanner quantification of PI uptake in all toxicity studies performed. Treatments that do not enhance the expression of GluR2S880ct (stretch alone, or $10 \mu \mathrm{M}$ NMDA alone) do not increase the vulnerability of cortical cells to subsequent challenge of $30 \mu \mathrm{M}$ AMPA. (f) Antagonizing NR2b-contaning NMDA receptors attenuates the injury-induced increase in GluR2 phosphorylation. (g) NR2A antagonism does not reduce GluR2 phosphorylation. ERK1,2 was used as a loading control. ${ }^{*} P<0.01$
} 
a

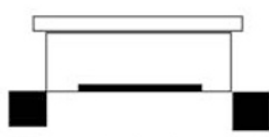

Primary cortical cultures plated onto silastic membrane and grown for $11-14$ days

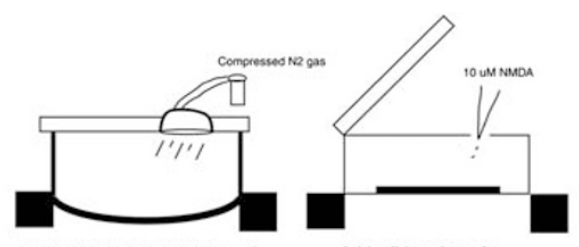
2.5-2.9 pounds per square inch ( $-9.5 \mathrm{~N} . \mathrm{s}$ impulse)

Add mild excitotoxin b

Add sublethal stretch injury of

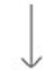

Incubate 1 hour

Functional Assays:

Phosphorylated GluR

- AMPAR mEPSCS

- Co-precipitation of

AMPAR trafficking

proteins
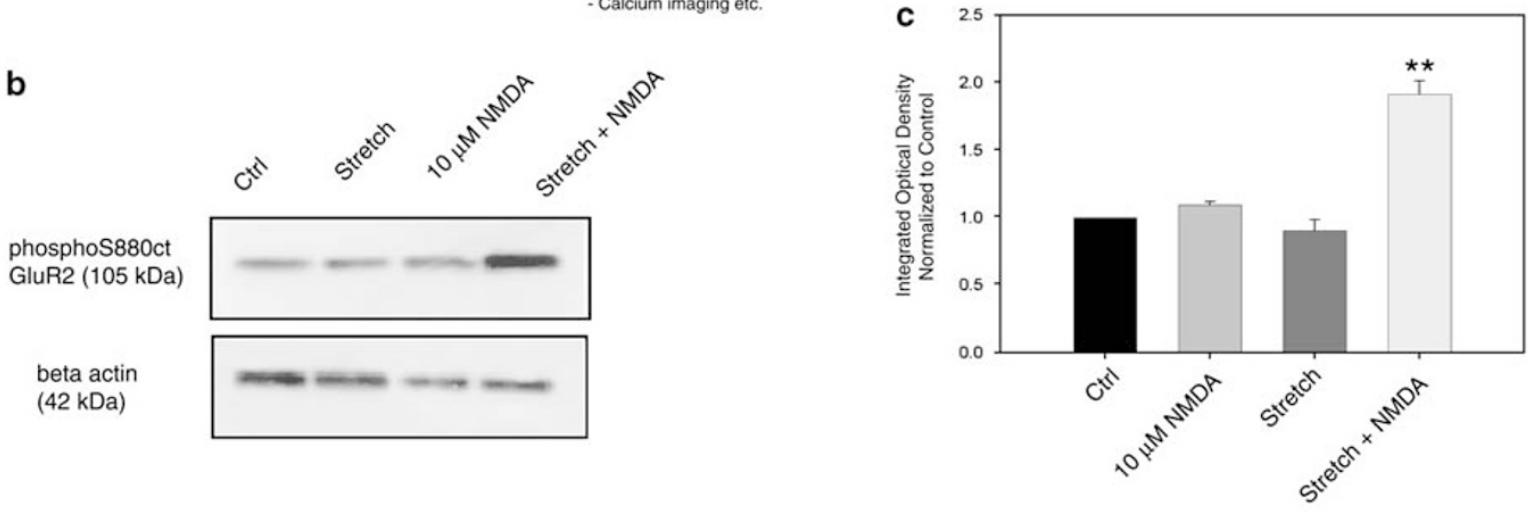
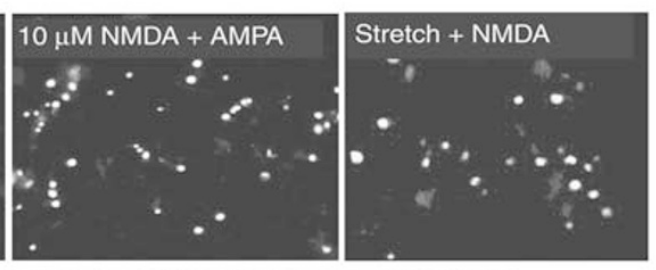

Stretch + NMDA + AMPA
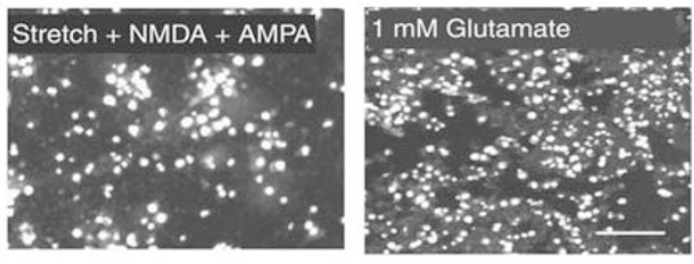

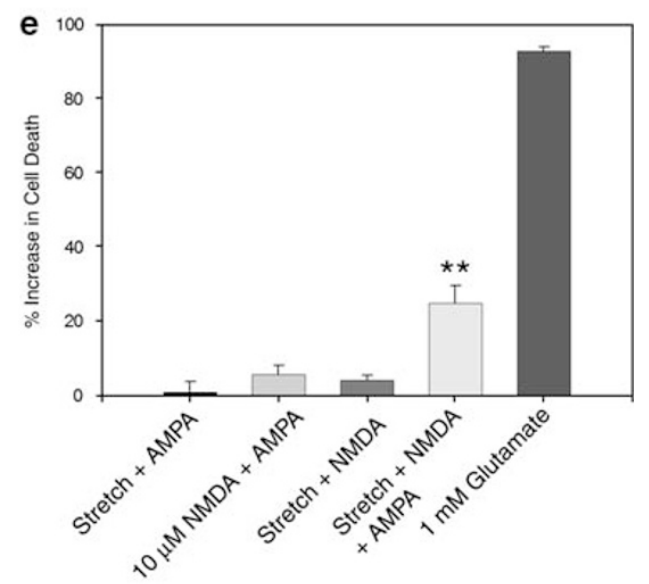

f

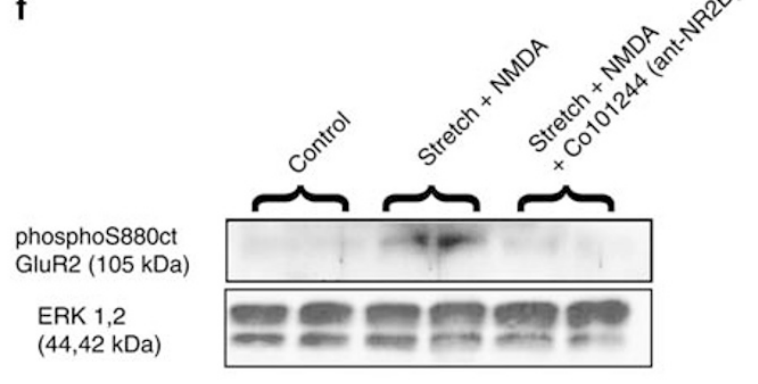

g

phosphos880ct GluR2 (105 kDa)

ERK 1,2

$(44,42 \mathrm{kDa})$

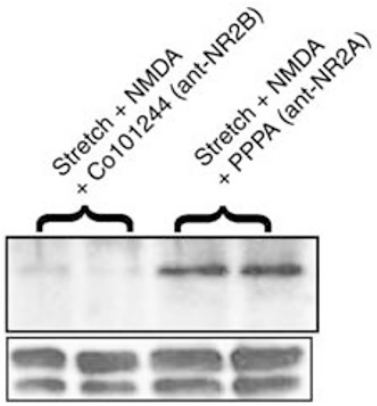


control, $P<0.01$ compared to stretch + NMDA) as well as TAT-QSAV $(123 \pm 9.2 \%$ of control, $P<0.05$ compared to stretch + NMDA) attenuated the increase in PKC $\alpha-P S D-95$ binding (Figure 2i-k). TAT-AAAA had no observable effect ( $171 \pm 22.4 \%$ of control, $P<0.01$ relative to control, Figure $2 \mathrm{j}$ and $\mathrm{k}$ ). This structural association between PKCa and the NMDAR complex is a novel finding that sheds further mechanistic light on how signaling at NR2b-containing NMDARs leads to post-traumatic GluR2 phosphorylation, and ultimately, endocytosis. a
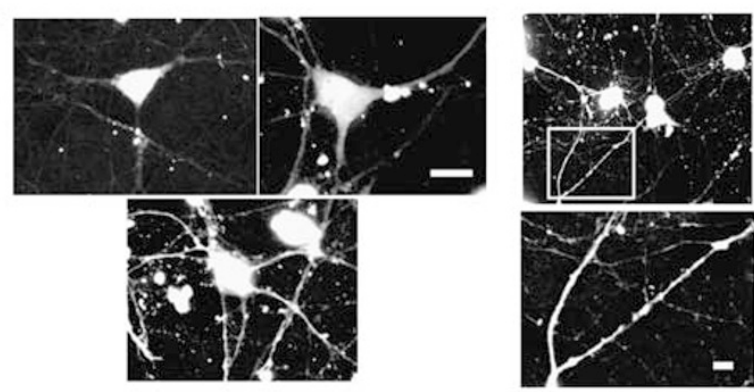

b IP: PICK1

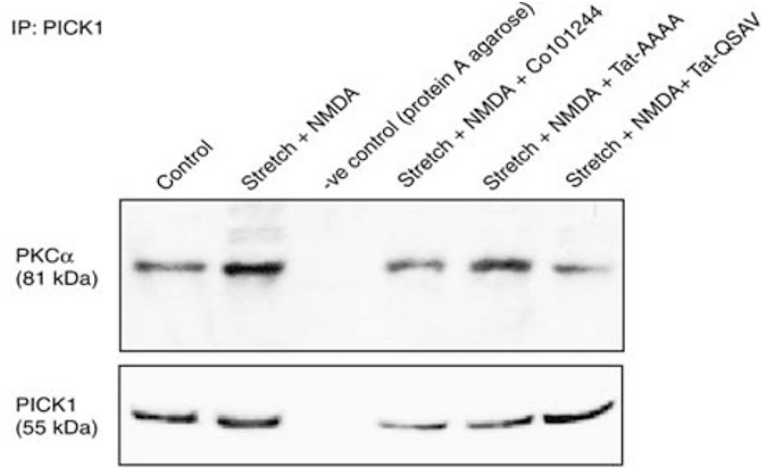

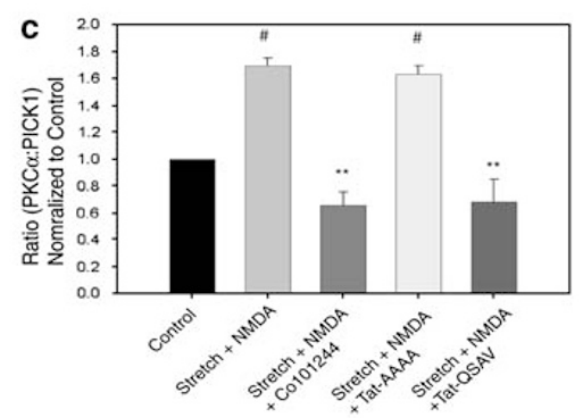

d

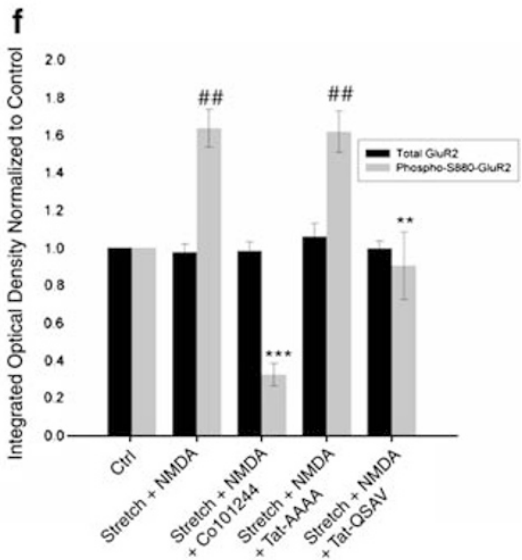

g

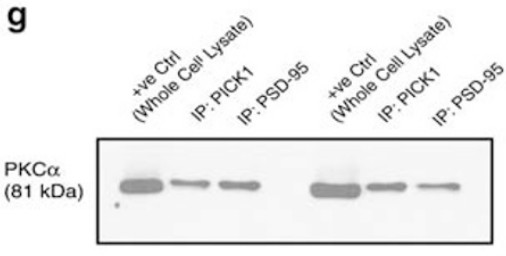

h

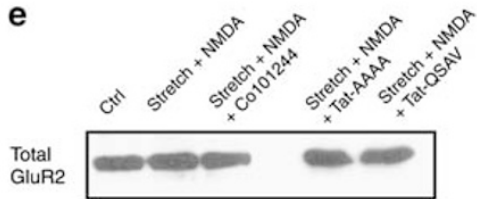

i

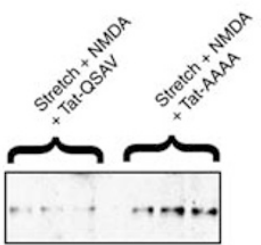

ERK 1/2 (44,42 kDa)
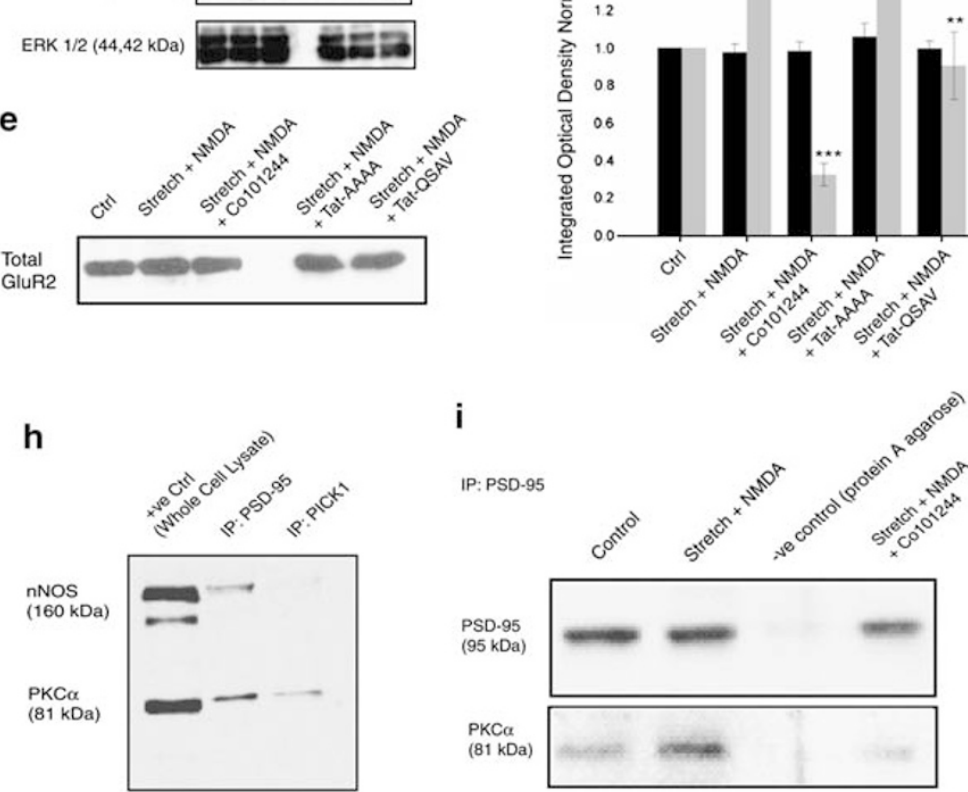

j IP: PSD.95

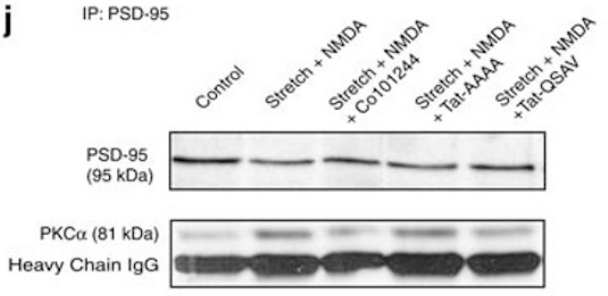

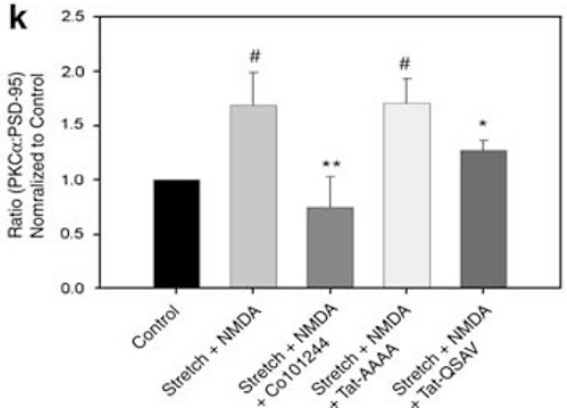


Stretch + NMDA increases GluR2 endocytosis. Acid-strip immunofluorescence showed significant internalization of GluR2 after stretch + NMDA (ratio of internal GluR2/ dendrite area $=0.038 \pm 0.003$ relative to $0.012 \pm 0.001$ in control cultures, $P<0.001$, Figure $3 a$ and b). As bath application of NMDA causes GluR2 endocytosis, controls were run with both 10 and $50 \mu \mathrm{M}$ NMDA alone (the latter as a positive control); $10 \mu \mathrm{M}$ NMDA on its own did not increase internalized GluR2 (ratio $=0.009 \pm 0.002,10 \mu \mathrm{M}$ NMDA versus $0.012 \pm 0.001$, control, $P>0.05$, Figure $3 a$ and $b$ ), a stark contrast to the effect of this dose of NMDA when combined with stretch injury. As expected, $50 \mu \mathrm{M}$ NMDA did cause a significant increase in internalized GluR2 (ratio $=0.029 \pm 0.005, \quad P<0.01$ versus control, $P>0.05$ versus stretch $+10 \mu \mathrm{M}$ NMDA). Thus, we observed that stretch injury significantly augmented the GluR2 endocytotic response of a low dose of NMDA, with a synergistic effect of the mechanical injury and the excitotoxin similar to what was observed in the assays of GluR2 phosphorylation. NR2b antagonism significantly reduced GluR2 internalization (ratio $=0.023 \pm 0.0004, P<0.05$ relative to stretch + NMDA), as did TAT-QSAV (ratio $=0.022 \pm 0.004$, $P<0.05)$. The compounds did not differ significantly in their levels of attenuation $(P=0.47)$.

Relative to control cultures $(0.37 \pm 0.01$ spines per $\mu \mathrm{m}$, mean spine head diameter $=0.76 \pm 0.04 \mu \mathrm{m}, n=21$ cells) stretch + NMDA had the incidental effect of decreasing dendritic spine density and increasing the mean diameter of remaining spine heads $(0.26 \pm 0.02$ spines per $\mu \mathrm{m}$, mean spine head diameter $=1.14 \pm 0.06 \mu \mathrm{m}, n=28$ cells, $P<0.001$ relative to control for spine density and diameter, Figure $3 d$ and e). We hypothesized that GluR2 endocytosis was contributing to this morphological damage because surface GluR2 stabilizes dendritic spines. ${ }^{18}$ Indeed TAT-QSAV preserved dendritic spine density and reduced average spine size in injured neurons $(0.38 \pm 0.01$ spines per $\mu \mathrm{m}$, mean spine head diameter $=0.76 \pm 0.02 \mu \mathrm{m}, n=19$ cells, $P<0.001$ relative to injured (untreated) for spine density and mean diameter, Figure $3 c-e)$. There was no statistical difference between injured cultures treated with TAT-QSAV and uninjured cultures $(P=0.40$ for spine density, $P=0.49$ for spine diameter). NR2b antagonism resulted in a mean spine diameter similar to controls $(0.83 \pm 0.01 \mu \mathrm{m}, n=24$ cells, $P<0.001$ versus injured (untreated), $P=0.11$ versus control, Figure $3 e$ ) but did not rescue dendritic spine density $(0.29 \pm 0.01$ spines per $\mu \mathrm{m}, P=0.45$, Figure $3 \mathrm{~d})$ suggesting that NMDAR blockade was less effective in restoring normal dendrite morphology relative to the TAT-QSAV peptide.
These results suggest that preventing GluR2 endocytosis also helps preserve neuronal morphology after traumatic injury.

Stretch + NMDA increases GluR1 S845 phosphorylation,
potentiates AMPAR-mediated mEPSCs, and confers
mEPSC sensitivity to polyamines. Mild mechanical trauma coupled with NMDA receptor activation produces high levels of nitric oxide (NO) through the NR2b-PSD-95nNOS cascade in cortical neurons. ${ }^{19}$ Accordingly, we also investigated NO-dependent GluR1 phosphorylation at S845, a protein modification that increases GluR1 surface expression. ${ }^{20}$ After stretch + NMDA, phosphorylated GluR1 increased to $302 \pm 47.6 \%$ of control levels $(P<0.05$, Figure $4 a)$. Notably, cells treated with an NR2b antagonist did not exhibit a significant increase in phosphorylated GluR1 relative to control cultures ( $P=0.15$, Figure $4 a)$. We also probed simultaneously for total GluR1 levels, of which there was no significant difference between treatments $(P=0.71$, Figure $4 a)$.

It is known that GluR2-lacking AMPA receptors have a higher single-channel conductance than receptors containing GluR2 ${ }^{5}$ and are sensitive to polyamine antagonism. After stretch + NMDA, AMPAR-mediated mEPSCs indeed exhibited significantly larger amplitudes than control neurons $(26.76 \pm 1.62 \mathrm{pA}$ versus $18.33 \pm 0.69 \mathrm{pA}, P<0.01$, Figure $4 \mathrm{~b})$, as well as a $36.4 \pm 5.4 \%$ reduction in amplitude after application of 1-naphthyl-acetyl spermine (naspm), a polyamine antagonist of GluR2-lacking but not GluR2-containing AMPARs (Figure 4c). Control mEPSCs did not show naspm sensitivity $\quad($ control + naspm $=18.38 \pm 0.81 \mathrm{pA})$, consistent with the presence of predominantly GluR2-containing AMPARs in control cortical neurons. Naspm treatment did not significantly alter the frequency of mEPSCs (control + naspm $=0.36 \pm 0.04 \mathrm{~Hz} ; \quad$ control alone $=0.43 \pm 0.01 \mathrm{~Hz}$; injury $=0.31 \pm 0.06 \mathrm{~Hz} ; \quad$ injury + naspm $=0.45 \pm 0.01 \mathrm{~Hz}$, Figure 4d). TAT-QSAV likewise reduced mEPSC amplitudes in injured cultures to $14.72 \pm 0.95 \mathrm{pA}$. TAT-AAAA treatment reduced amplitudes to $22.13 \pm 0.58 \mathrm{pA}$. Both treatment amplitudes were significantly lower than injury levels (Figure $4 \mathrm{e}$ and f). However, mEPSCs were significantly reduced in QSAV-treated cultures relative to AAAA-treated cultures $(P<0.05)$, suggesting a significant effect of PICK1 inhibition independent of any effects that peptide transduction alone may have on excitability (Figure 4f).

Stretch + NMDA causes calcium influx through calciumpermeable AMPARs. We next visualized post-injury intracellular calcium dynamics after perfusion with AMPA (schematic

Figure 2 Stretch + NMDA confers association of PKC $\alpha$ with both PICK1 and PSD-95. (a) Dansyl chloride-conjugated TAT peptides (10 $\mu$ M) successfully transduce live cortical cultures (images taken at 20 min after peptide application). Scale bars: $10 \mu \mathrm{m}$ low magnification, $2 \mu \mathrm{m}$ high magnification. (b) Stretch + NMDA promotes an NR2bdependent association of PKC $\alpha$ with PICK1. TAT-QSAV, relative to TAT-AAAA and injured (untreated) cultures, markedly diminishes bound levels of PKC $\alpha$ to PICK1. Membranes were stripped and re-probed for PICK1. (c) Quantification of data presented in (b). Data are expressed as the ratio of PKC $\alpha / P I C K 1$, and each condition is normalized to control levels. (d) TAT-QSAV, but not TAT-AAAA, also reduces post-traumatic S880 phosphorylation of GluR2. (e) Total GluR2 does not change in any of the treatment conditions. (f) Quantification of total and phosphorylated GluR2 across conditions. (g, h) PKC $\alpha$ co-immunoprecipitates with PSD-95 in cortical cell lysates. PICK1 I.P was used as a positive control for the PKC $\alpha$ immunoblot in (g), and blotting for nNOS was used as a positive control for the PSD-95 I.P in (h). Note the lack of nNOS in the PICK1 I.P. (i) PKC $\alpha$ and PSD-95 exhibit a stronger interaction after Stretch + NMDA. Antagonism of NR2b-containing NMDA receptors with Co101244 attenuates this increase. Membranes were stripped and re-probed for PSD-95. (j) Identical co-immunoprecipitation experiments as outlined in (i), using a polyclonal antibody to PKC $\alpha$. This antibody also recognized higher levels of bound PKC $\alpha$ to PSD-95 in conditions in which GluR2 phosphorylation was increased. TAT-QSAV attenuates the injury-induced increase in PKC $\alpha$-PSD-95 co-immunoprecipitation (far right lane), but TAT-AAAA is ineffective. (k) Quantification of co-precipitated PKC $\alpha$ with PSD-95, expressed as the ratio of PKC $\alpha /$ PSD-95, and normalized to control values. ${ }^{\#} P<0.05$ versus control; ${ }^{\# \#} P<0.01$ versus control ${ }^{* \star} P<0.01 ;{ }^{* \star *} P<0.001 ;{ }^{*} P<0.05$ 

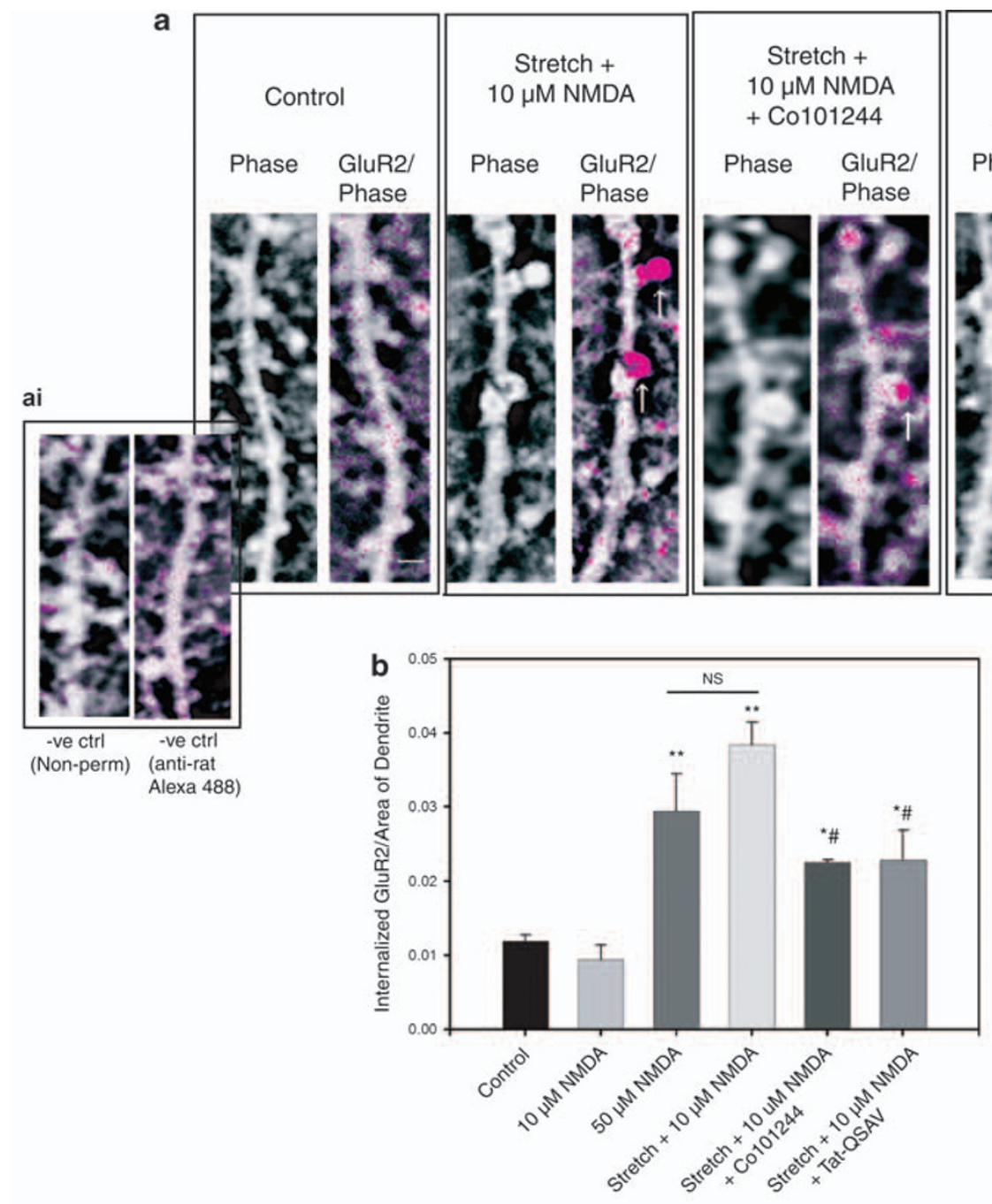

C

Stretch + NMDA (untreated)

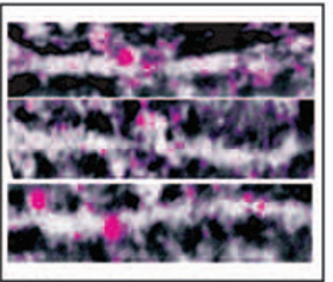

Stretch + NMDA + Tat-QSAV

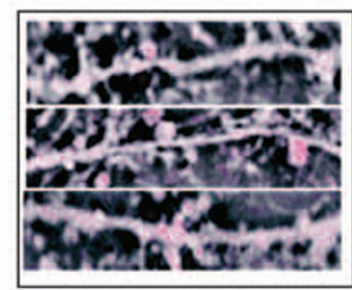

d

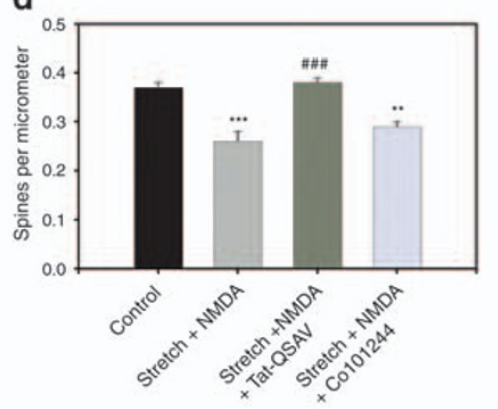

Stretch +

$10 \mu \mathrm{M}$ NMDA

+ Tat-QSAV

$10 \mu \mathrm{M}$ NMDA

+ Co101244

GluR2/
Phase
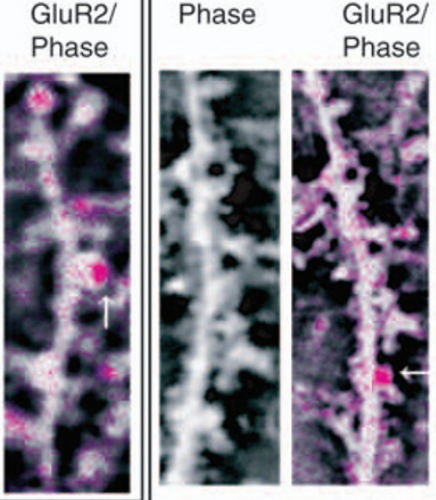

No Stretch

$10 \mu \mathrm{M} \quad 50 \mu \mathrm{M}$ NMDA NMDA

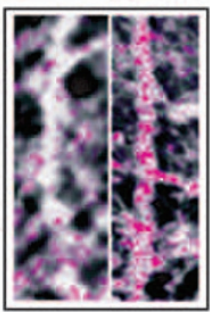

Figure 3 Stretch + NMDA increases GluR2 endocytosis. (a) Inverted confocal phase contrast images of cortical dendritic spines were overlayed with staining of internalized GluR2 after acid stripping. Stretch $+10 \mu \mathrm{M}$ NMDA conferred distinct GluR2-positive puncta in dendritic spines, whereas control neurons did not (far left panel). NR2b antagonism (C0101244) and TAT-QSAV significantly decrease GluR2 internalization after Stretch + NMDA, but GluR2 endocytosis was still higher than controls. In all conditions, arrows indicate spines that stained positively for internalized GluR2; $50 \mu \mathrm{M}$ NMDA was used as a positive control, and resulted in intense staining along the dendrite of internalized GluR2. (ai) Negative controls of non-permeabilized cells, and cultures treated only with secondary antibody. (b) Quantification of immunofluorescent data expressed as the ratio of internalized GluR2/area of dendrite. ${ }^{*} P<0.05$ versus control, ${ }^{\#} P<0.05$ versus injured, ${ }^{\star \star} P<0.01$ versus control; Scale bars $=2 \mu \mathrm{m}$. (c) Representative confocal images of dendritic morphology in injured, untreated neurons (left panel) and in injured neurons treated with $10 \mu \mathrm{m}$ TAT-QSAV. Overlay represents internalized GluR2. Note that in the absence of internal GluR2 staining, dendritic spine density is increased. Scale bars $=2 \mu \mathrm{m}$. (d) Quantification of dendritic spine density as spines per $\mu \mathrm{m}$. (e) Quantification of mean dendritic spine head diameter $(\mu \mathrm{m}) .{ }^{* \star} P<0.001$ versus control; ${ }^{\star \star} P<0.01,{ }^{\# \# \#} P<0.001$ versus injured

in Figure 5a). Baseline calcium of control neurons was significantly lower than in neurons exposed to stretch + NMDA $(0.11 \pm 0.01$ versus $0.19 \pm 0.01$, respectively, $P<0.01$,
Figure $5 \mathrm{~b}$ and $\mathrm{c}$ ), indicating the insult affected cytosolic $\mathrm{Ca}^{2+}$ levels before AMPAR stimulation. After applying AMPA, peak emissions normalized to baseline ratios did not differ between 
a

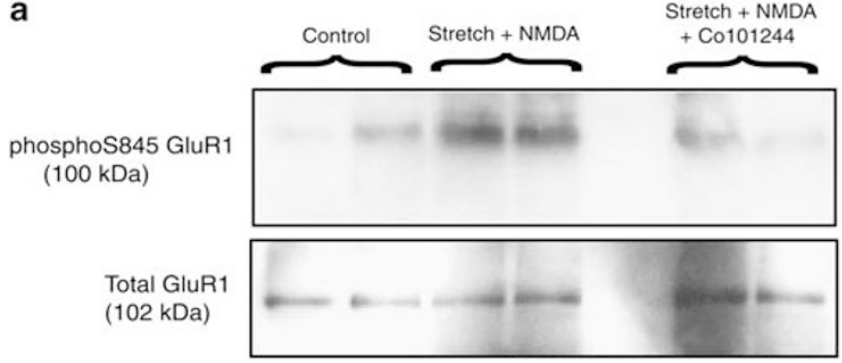

b
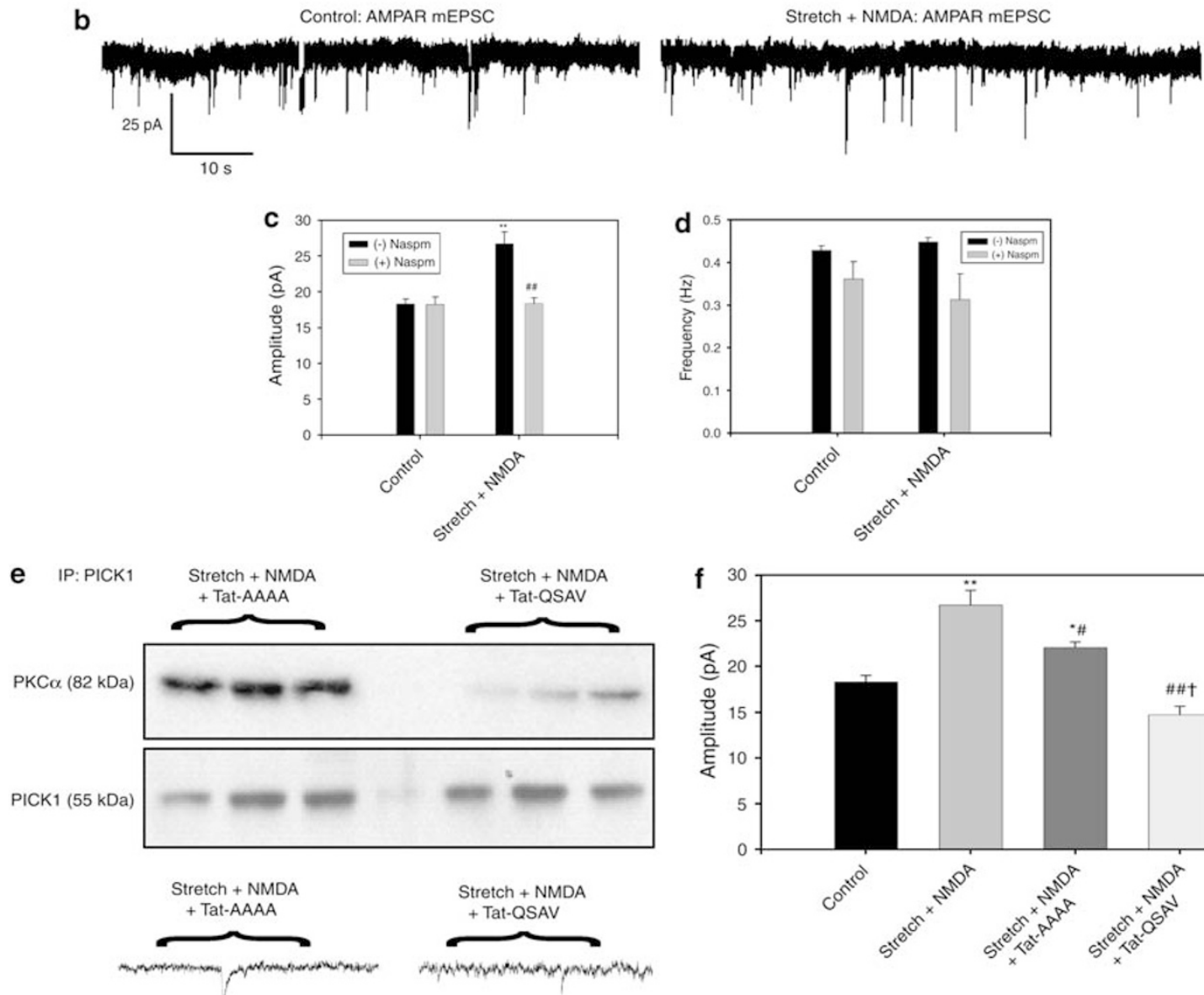

Stretch + NMDA: AMPAR mEPSC
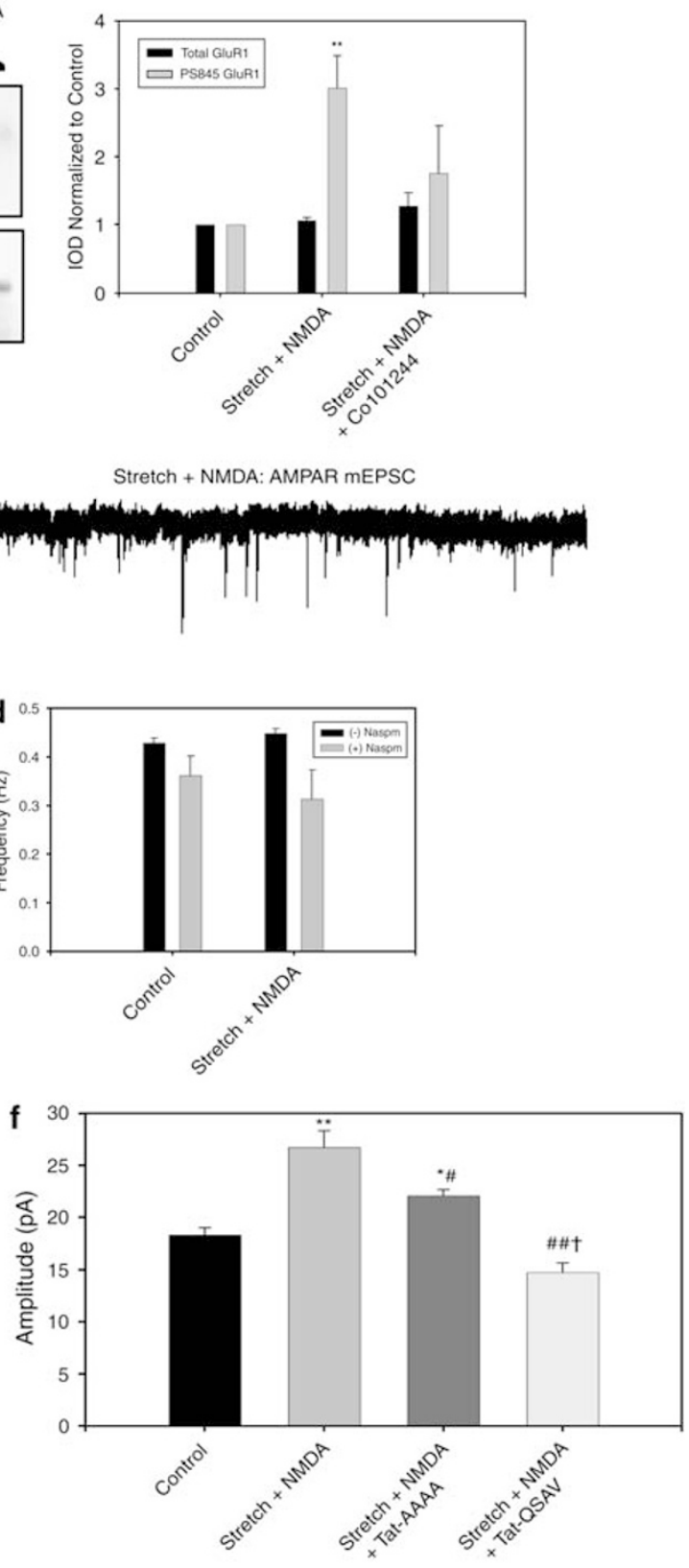

Figure 4 Stretch + NMDA increases GluR1 S845 phosphorylation and confers mEPSC polyamine sensitivity. (a) GluR1 S845 increases after Stretch + NMDA and is mitigated by $\mathrm{NR} 2 \mathrm{~b}$ antagonism (quantification on right). (b) Representative AMPAR-mediated mEPSC traces of injured and control neurons ( $1 \mathrm{~h}$ after insult) showing an increase in average mEPSC amplitude. (c) AMPAR-mediated mEPSCs show a selective sensitivity to polyamine antagonism (Naspm) of GluR2-lacking receptors. (d) mEPSC frequency is unaffected by Naspm. (e) Post-injury co-precipitation of PICK1 and PKC $\alpha$ in the presence of TAT-QSAV and TAT-AAAA and resultant mEPSC activity. QSAV-treated neurons exhibited a significant reduction from AAAA-treated cells in mEPSC amplitude and bound PKC $\alpha / P I C K 1$. (f) Quantification of mEPSC amplitudes in all conditions. Neurons were held at $-70 \mathrm{mV}$. ${ }^{*} P<0.01$ versus control; ${ }^{*} P<0.05$ versus control; ${ }^{\# \#} P<0.01$ versus injured; ${ }^{\#} P<0.05 ;{ }^{\dagger} P<0.01$ versus TAT-AAAA 
control and injured neurons $(2.07 \pm 0.45 \times$ baseline versus $1.84 \pm 0.12 \times$ baseline, respectively, $P=0.19$ ) (Figure $5 \mathrm{~b}$ and e). However, injured neurons exhibited significantly longer calcium extrusion times $(5.93 \pm 1.59$ min versus $1.65 \pm$ $0.51 \mathrm{~min}$, respectively, Figure $5 \mathrm{~b}$ and $\mathrm{d} P<0.01)$. Integration for the area under the curve as a surrogate indicator of

a
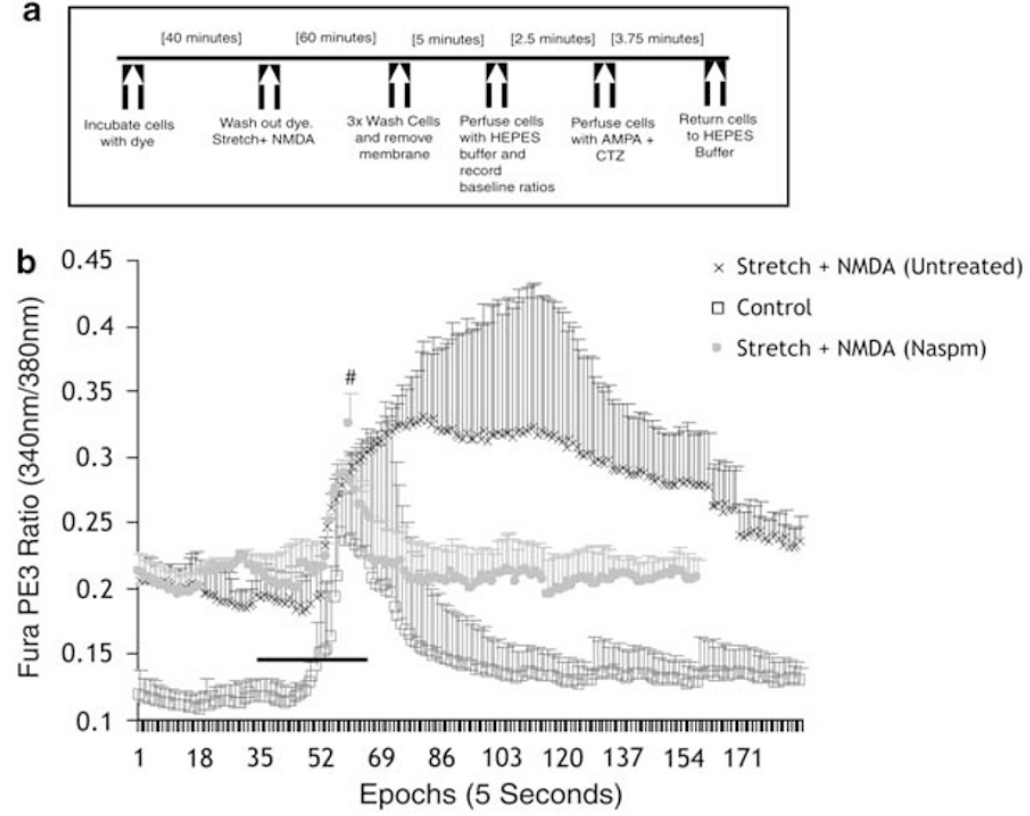

C

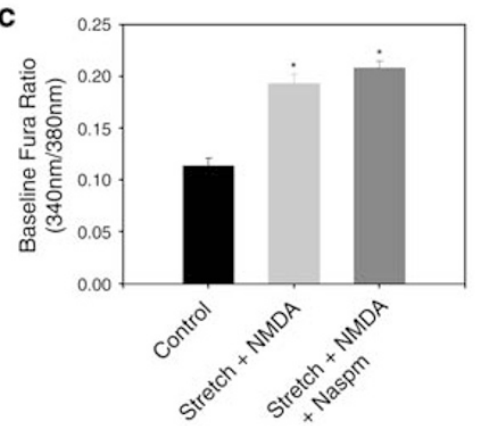

e

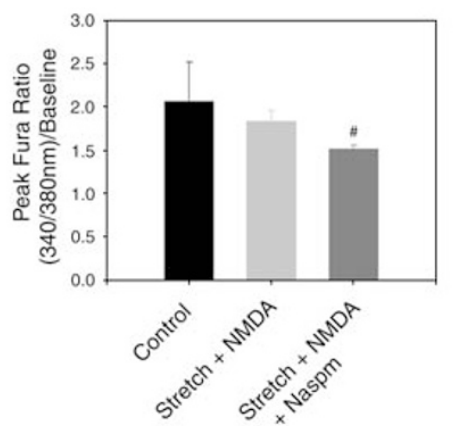

h

Control AMPAR mEPSC (Sodium-Free)

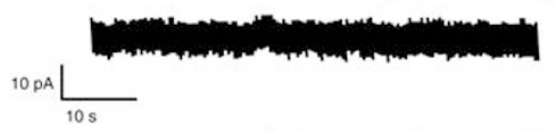

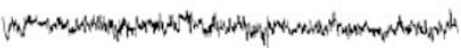

$7 \mathrm{pA} \mathrm{L}_{30 \mathrm{~ms}}$ d
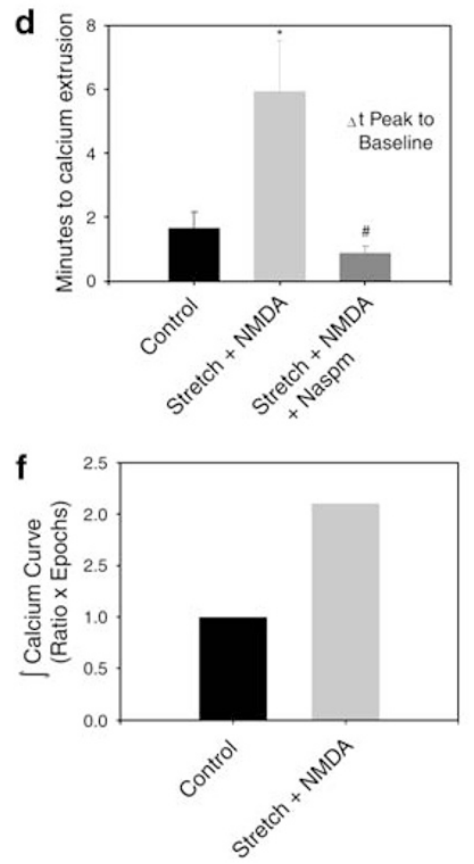

i

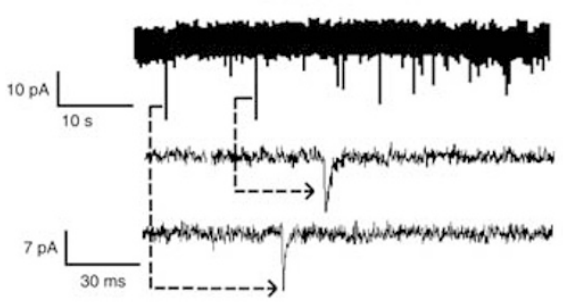

Baseline
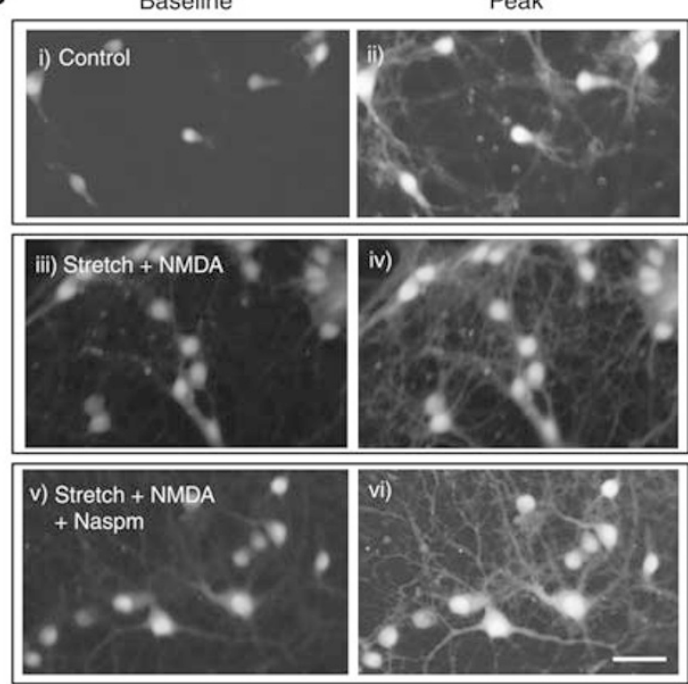
intracellular calcium levels indicated a 2.11-fold larger area relative to control neurons (62.37 ratio - epochs versus 29.62 ratio $\cdot$ epochs, Figure $5 \mathrm{f})$.

We tested the efficacy of naspm in reducing peak $\mathrm{Ca}^{2+}$ in injured neurons and improving calcium extrusion. Baseline calcium of naspm-treated injured cells was comparable to injured (untreated) cells $(0.21 \pm 0.01$ versus $0.19 \pm$ 0.01 , respectively, $P=0.13$, Figure $5 b$ and $c)$, suggesting that GluR2-lacking AMPARs were not responsible for the initial trauma-induced elevation of baseline emission ratios. However, after AMPA application, peak calcium was significantly lower in naspm-treated injured cells relative to injury (untreated) $(1.52 \pm 0.04 \times$ baseline, $P<0.01$ versus values for injury, Figure $5 \mathrm{e}$ and $\mathrm{g}$ ), suggesting a contribution of calcium-permeable AMPARs in the initial rise of $\mathrm{Ca}^{2+}$ in injured neurons during perfusion of AMPA. We have shown earlier that naspm does not impact $\mathrm{Ca}^{2+}$ influx in control neurons. ${ }^{9}$ Further, the time from peak to extrusion in naspm-treated injured neurons was $0.88 \pm 0.21 \mathrm{~min}$, a significant reduction from that of injured (untreated) cells $(P<0.05)$ but not of control cells $(P=0.12$, Figure $5 \mathrm{~b}$ and $\mathrm{d})$. Integration of the naspmtreated calcium curve yielded a value of 28.29 ratio-epochs, a value similar to that obtained from control cultures (29.62 ratio - epochs). Further, sodium-free wholecell patch clamp of injured neurons showed markedly increased activity (qualitatively, Figure 5i). Sodium-free firing of injured neurons could not be replicated in the presence of neuronal NO synthase inhibition, (Figure 5j), supporting the hypothesis that NO-dependent S845 GluR1 phosphorylation was critical in the sodium-free activity.

Neuroprotection of cortical neurons by inhibiting GluR2 endocytosis. We repeated the earlier toxicity assays of stretch + NMDA followed $1 \mathrm{~h}$ later by a $30 \mu \mathrm{M}$ AMPA challenge. Post-injury treatments included $20 \mu \mathrm{M}$ TATQSAV, $20 \mu \mathrm{M}$ TAT-AAAA, and $100 \mu \mathrm{M}$ naspm. Stretch + NMDA again resulted in a marked susceptibility to secondary AMPA toxicity $(23.3 \pm 5.9 \%$ increase in cell death, $n=3$ cultures; Figure 6b). However, TAT-QSAV applied with stretch + NMDA afforded significant cytoprotection against AMPA excitotoxicity $20 \mathrm{~h}$ after injury $(9.58 \pm 2.9 \%$ increase in cell death, $n=4$ cultures, $P<0.05$, Figure $6 \mathrm{~b}$ ). Naspm also showed a trend toward cytoprotection against cell death conferred by AMPA $(1.78 \pm 5.7 \%$ increase in cell death, $n=3$ cultures, $P=0.055$, Figure $6 \mathrm{~b})$. TAT-AAAA showed no attenuation of AMPA-induced cell death $(29.2 \pm 3.9 \%$ increase in cell death, $n=3$ cultures; Figure $6 b$ ). Importantly, there was no significant difference in cell death between groups at $1 \mathrm{~h}$ after the insult. These results suggest that a portion of the delayed (i.e. secondary) cell death that occurs in this model of trauma could be prevented through preservation of surface GluR2 or antagonizing GluR2-lacking AMPARs.

In vivo TBI results in GluR2 phosphorylation and association of the subunit with PICK1. We next assayed cortical and hippocampal GluR2 phosphorylation in animals subjected to fluid percussion injury (FPI). Phosphorylated GluR2 was markedly increased in the cortex (247.2 $\pm 31.2 \%$ of control animals, $n=6, \quad P<0.01)$ and hippocampus $(251.5 \pm 43.1 \%$ of control, $n=5, P<0.01)$ of injured animals (Figure 7a, cortical blots shown). We also observed significantly more GluR2 $(141 \pm 11.8 \%$ of control, $P<0.05$, Figure 7c) bound to PICK1 in cortical lysates taken post FPI (Figure $7 \mathrm{~b}$ and e), a biochemical indication of subunit internalization early after trauma. After showing successful perturbation of the PICK1-PKC $\alpha$ protein interaction with TATQSAV, but not with TAT-AAAA (Figure 7d), we observed that intraperitoneal injection $(1 \mathrm{mg} / \mathrm{kg})$ of TAT-QSAV significantly inhibited the association of GluR2 with PICK1 after FPI (Figure 7e and $\mathrm{f} ; n=5, P<0.01$ ), suggesting this peptide successfully interferes with post-traumatic mechanisms of GluR2 internalization in vivo. Intravenously administered TAT-AAAA at $3 \mathrm{mg} / \mathrm{kg}$ (triple the dose of TAT-QSAV) did not influence the characteristic increase in the GluR2-PICK1 interaction after FPI (145.6 $\pm 24.1 \%$, Figure $7 e$ and $f, P<0.05$ versus $Q S A V$ and sham, $P>0.05$ versus $\mathrm{FPI})$.

Post-traumatic expression of hippocampal calciumpermeable AMPA receptors is inhibited by TATQSAV. We last investigated whether a traumatically injured hippocampus showed an increased expression of calciumpermeable AMPARs, as these receptors contribute to progressive excitotoxic cell death and dysfunction. ${ }^{6-10,21,22}$ We found during recordings from FPI rats that CA1 population spikes exhibited a naspm-induced rundown to $58.9 \pm 1.7 \%$ of baseline, a significantly greater inhibition than sham animals (78.9 $\pm 0.79 \%, \quad P<0.05$, Figure 7g). However, injecting animals intravenously with TAT-QSAV $(3 \mathrm{mg} / \mathrm{kg})$ after the traumatic injury occluded naspm-induced rundown of CA1 population spike amplitude (88.2 $\pm 5.6 \%$, Figure $7 \mathrm{~h})$. Notably, naspm sensitivity was preserved in TAT-AAAA injected animals $(59.3 \pm 8.3 \%$ of baseline, $P<0.01$ versus sham and

Figure 5 Stretch + NMDA promotes calcium influx through calcium-permeable AMPARs. (a) Temporal schematic of calcium imaging experiments. (b) Fura PE3 data over the entire recording period. Baseline ratios of neurons exposed to Stretch + NMDA are significantly higher than those of control neurons. As well, after perfusion of $100 \mu \mathrm{M}$ AMPA and $50 \mu \mathrm{M}$ CTZ the duration of excess cytosolic $\mathrm{Ca}^{2+}$ is prolonged. Selective antagonism of GluR2-lacking AMPARs (100 $\mu$ M Naspm) lowers peak AMPA-induced $\mathrm{Ca}^{2+}$ and mitigates the prolonged elevation in intracellular calcium. (c) Quantification of baseline Fura ratios $(340 / 380 \mathrm{~nm})$. (d) Quantification of $\Delta t$ of peak calcium levels to return to baseline. (e) Quantification of peak ratio normalized to baseline; $100 \mu \mathrm{M}$ Naspm reduces peak calcium. (f) Integration of the calcium curves shown in (b) shows a 2.11-fold increase in the area under Stretch + NMDA curve relative to control neurons. There are no error bars in this graph because these are the integrals of the mean calcium curves. (g) Representative Fura-PE3 micrographs of baseline (left column) and peak (right column) emission in control neurons (top row), Stretch + NMDA (middle row) and Stretch + NMDA $+100 \mu \mathrm{M}$ Naspm (bottom row). Scale bars $=40 \mu \mathrm{m}$. (h) Removal of extracellular sodium abolishes AMPAR-mediated mEPSCs in cortical neurons held at $-70 \mathrm{mV}$. (i) AMPAR mEPSCs persist in the absence of extracellular sodium in cortical neurons $1 \mathrm{~h}$ after Stretch + NMDA. (j) Addition of $100 \mu \mathrm{M}$ L-NAME to inhibit nNOS and GluR1 phosphorylation largely attenuates the sodium-free firing in injured cortical neurons. ${ }^{*} P<0.05$ versus control; ${ }^{\#} P<0.05$ versus injury 
a
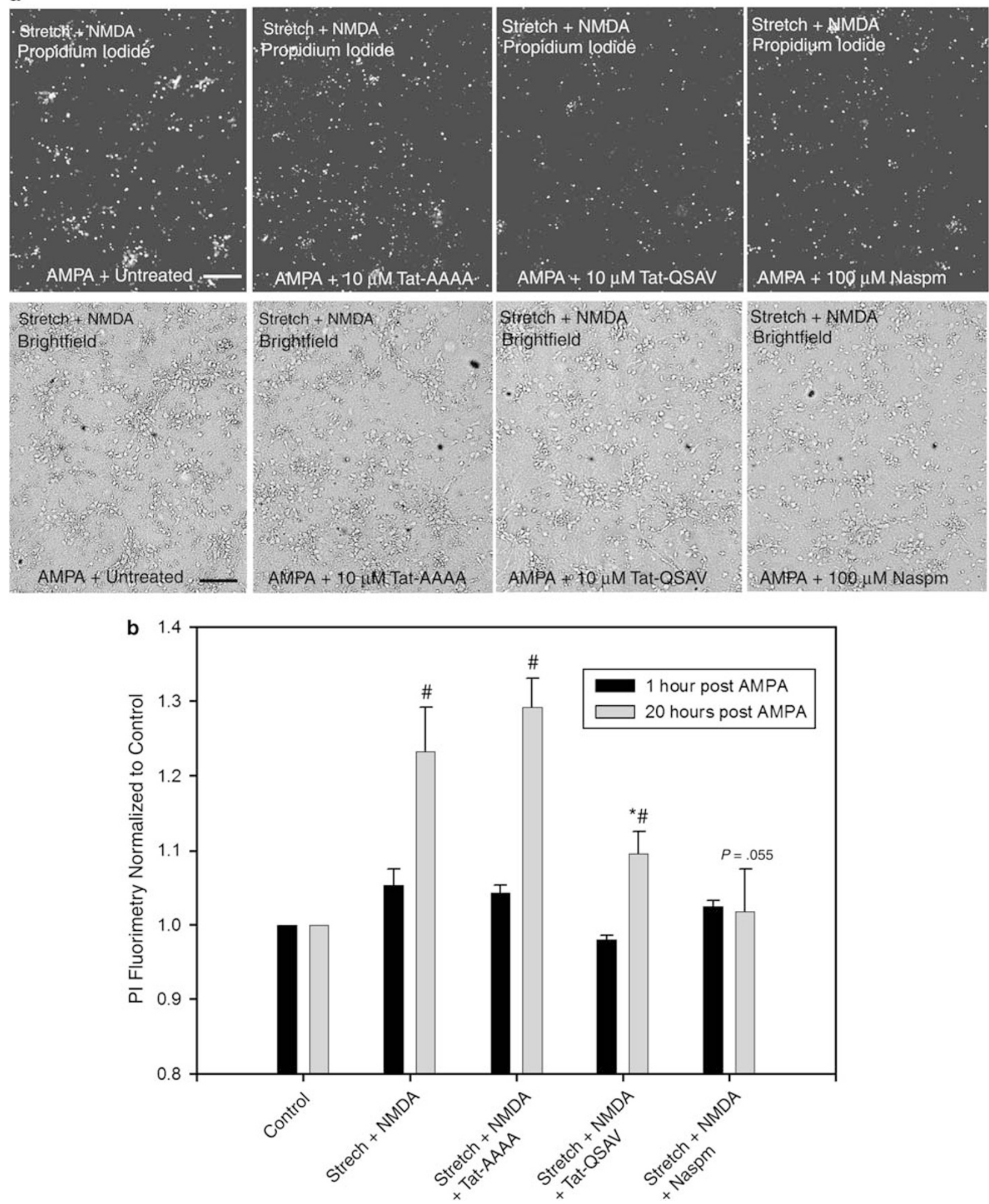

Figure 6 Inhibiting GluR2 endocytosis is neuroprotective. (a) Top row: representative propidium iodide fluorimetry $20 \mathrm{~h}$ after exposure of cortical neurons to Stretch + NMDA + AMPA, with or without the presence of polyamines or inhibitory peptides. AMPA was applied for $1 \mathrm{~h}$, with or without peptide/polyamine treatment, at $1 \mathrm{~h}$ after Stretch + NMDA. Bottom row: brightfield images of the corresponding field represented in top row. (b) Quantification of normalized PI fluorimetry by plate scanning at 1 and $20 \mathrm{~h}$ after AMPA treatment. Scale bar $200 \mu \mathrm{m} .{ }^{\#} P<0.05$ versus control; ${ }^{*} P<0.05$ versus injured 

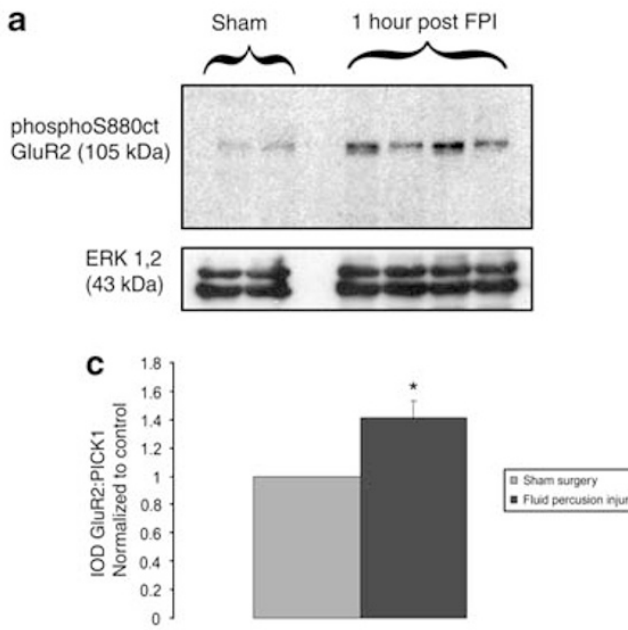

e

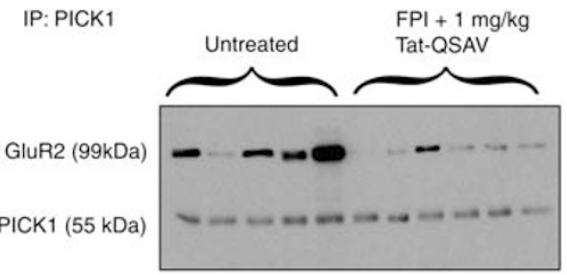

IP. PICK 1

GluR2 (99kDa)

PICK1 (55 kDa)

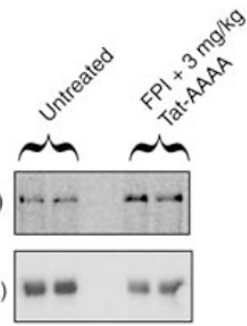

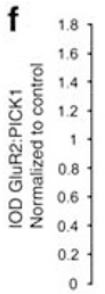

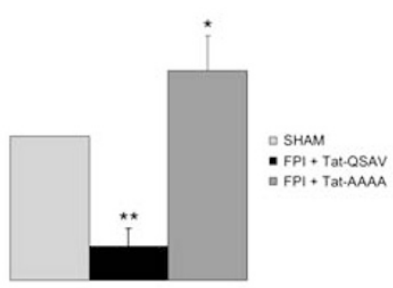

g

$\mathrm{FPI}+\mathrm{Naspm}$

h $\mathrm{FPI}+\mathrm{Tat}-\mathrm{QSAV}+\mathrm{Naspm}$

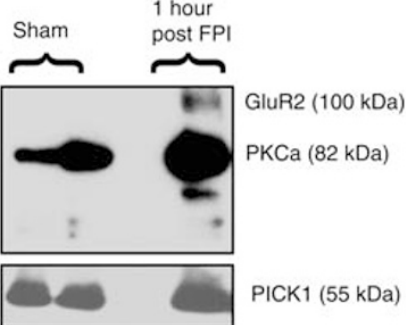

d IP: PICK

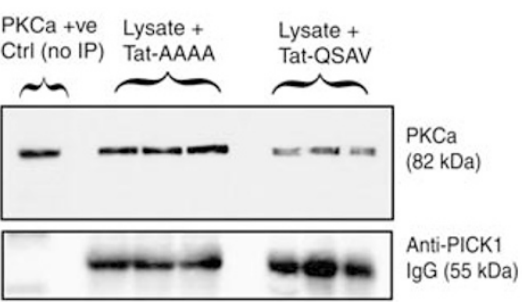

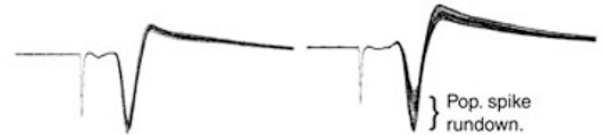

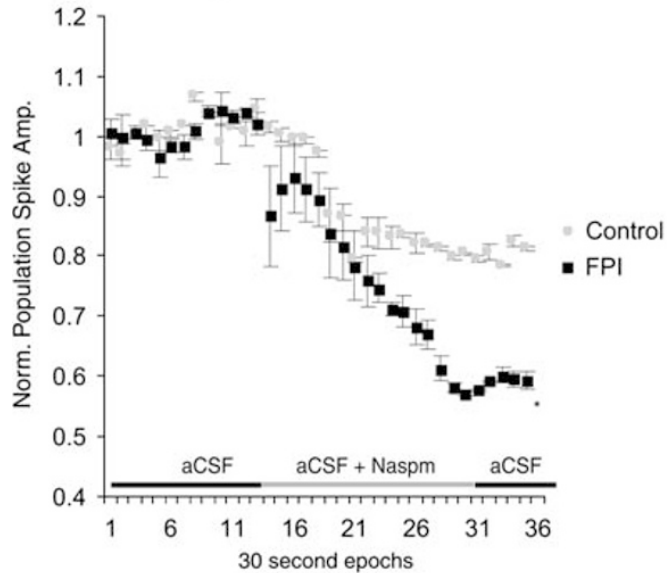

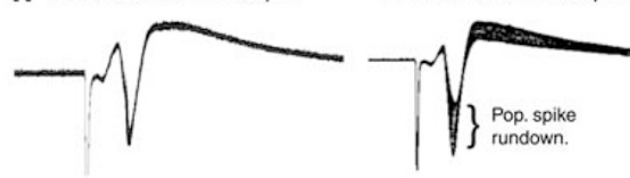

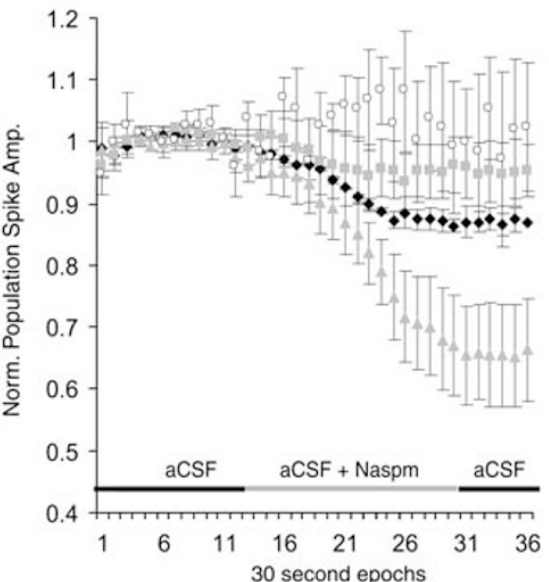

FPI + Tat-SVKI + Naspm

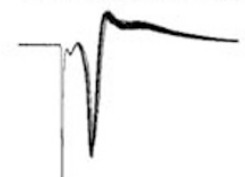

- Control

FPI + Tat-QSAV (3

$\mathrm{mg} / \mathrm{kg}$ )

FPI + Tat-AAAA (3

$\mathrm{mg} / \mathrm{kg}$ )

FPI + Tat-SVKI (3

$\mathrm{mg} / \mathrm{kg}$ )

Figure 7 In vivo traumatic brain injury (TBI) promotes GluR2 phosphorylation and association with PICK1, which imparts expression of calcium-permeable AMPARs. (a) Representative immunoblot of PS880 GluR2 in injured cortex $1 \mathrm{~h}$ after 2 atmosphere fluid percussion injury. ERK 1/2 is used as a loading control. (b) Representative coimmunoprecipitation of PICK1 with GluR2 and PKC $\alpha$ after forebrain trauma, showing GluR2 endocytosis $1 \mathrm{~h}$ after the injury (c) Quantification of all GluR2/PICK1 coprecipitation experiments. (d) TAT-QSAV, but not a control peptide, can perturb PICK1-PKC $\alpha$ protein interactions in vivo. (e) Animals treated after trauma with $1 \mathrm{mg} / \mathrm{kg}$ TATQSAV show significantly less co-precipitation of GluR2 with PICK1 $1 \mathrm{~h}$ after injury, suggesting this peptide can effectively prevent GluR2 endcocytosis in injured animals. TATAAAA has no effect on the injury-induced increase in GluR2/PICK1 (f) Quantification of GluR2/PICK1 co-precipitation with or without injection of TAT peptides. (g) CA1 hippocampal physiology is sensitive to antagonists of calcium-permeable AMPA receptors after TBI. Naspm-induced rundown of CA1 population spike amplitude was significantly greater in injured animals, supporting the in vitro findings that these molecular modifications lead to incorporation of phenotypically different channels. Representative traces illustrating rundown of population spike amplitude during the recording period appear above the graph. (h) Prevention of GluR2 endocytosis with TAT-QSAV or TAT-SVKI, both PICK1-binding peptides, significantly reduces CA1 naspm sensitivity. TAT-AAAA was ineffective in occluding naspm sensitivity. ${ }^{*} P<0.05{ }^{* *} P<0.05$ 


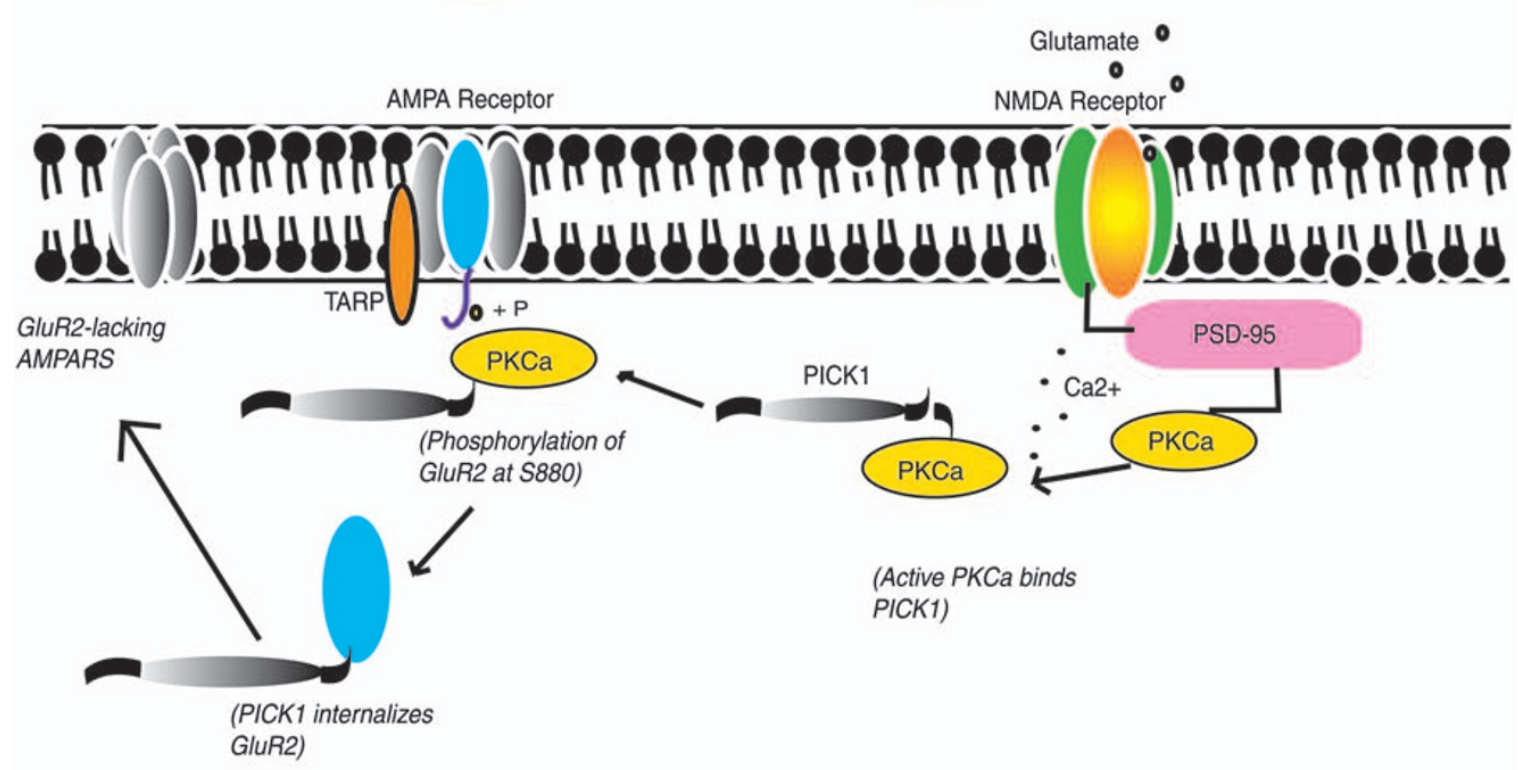

b

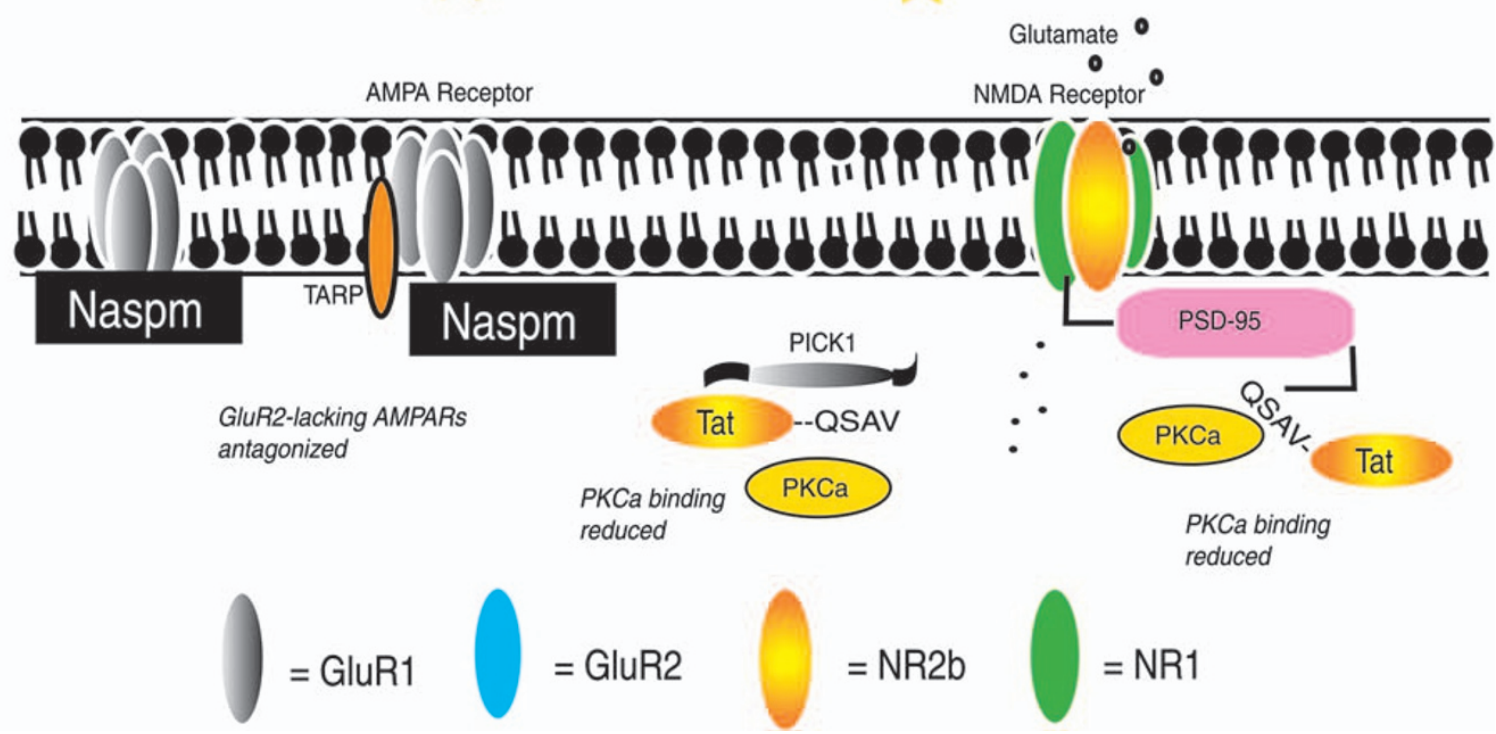

Figure 8 Schematic showing proposed signaling involved in post-traumatic internalization of GluR2 and subsequent expression of GluR2-lacking AMPARs. (a) After TBI, intracellular calcium coming through the NMDA receptor activates PKC $\alpha$ through its association with PSD-95 in the NMDAR complex. Activated PKC $\alpha$ binds PICK1, and is trafficked to the membrane in which it phosphorylates GluR2 at serine 880. GluR2 associates with PICK1 and is internalized from the cell surface, enhancing the expression of GluR2-lacking AMPARs. (b) Proposed mechanism of cytoprotection. Antagonism of GluR2-lacking AMPA receptors with Naspm, or occluding the binding of PKC $\alpha$ with PICK1 and/or PSD-95 through TAT-QSAV reduces GluR2 internalization and expression of calcium-permeable AMPARs after TBI

QSAV, $P>0.05$ versus FPI, Figure $7 \mathrm{~h})$. As a final positive control, we also treated animals $(3 \mathrm{mg} / \mathrm{kg})$ with a GluR2 c-terminal PICK1-binding peptide, TAT-SVKI. Naspm-induced population spike rundown was occluded $(97.2 \pm 14.1 \%$ of baseline, $P<0.05$ versus $\mathrm{FPI}$ ) in TAT-SVKI-treated animals in a similar manner to those animals treated with TAT-QSAV (Figure 7h), providing further evidence that PICK1-mediated GluR2 endocytosis was critical in the post-traumatic expression of calcium-permeable AMPARs.

\section{Discussion}

Here, we describe molecular and phenotypic alterations to AMPA receptor trafficking and physiology following in vitro and in vivo models of TBI. At the cellular level, we found that the endocytosis of surface GluR2 protein after trauma contributes to the expression of GluR2-lacking AMPARs, and the susceptibility of neurons to secondary injury. Accordingly, we suggest that preventing GluR2 internalization 
through TAT-QSAV-mediated inhibition of PICK1 is cytoprotective (Figure 8).

Consistent with the observations presented in this work, several other studies have proposed that loss of surface GluR2 contributes to secondary injury and neuronal death after CNS insult. First, ischemic incorporation of GluR2lacking AMPARs and association of GluR2 with PICK1 was reported in cultured hippocampal neurons. ${ }^{6}$ In that study, internalization of GluR2 was associated with a similar polyamine-sensitive increase in mEPSC amplitude. Subsequently, our lab reported PKC-dependent GluR2 internalization after mild stress injury in cerebellar Purkinje cells. In this scenario, the combination of naspm and PKC $\alpha$ inhibition was protective against secondary excitotoxicity. ${ }^{9}$ More recently, GluR2 S880 phosphorylation, GluR1 S845 phosphorylation and enhanced AMPAR mEPSCs were reported during neonatal epilepsy, a condition also marked by neuronal hyperexcitability. ${ }^{8}$ Finally, a switch from GluR2-containing AMPARs to GluR2-lacking AMPARs was reported after a more severe mechanical stretch injury - characterized by marked inward-rectification of the AMPA receptor currentvoltage relationship $-{ }^{10}$ in a study also showing neuroprotective effects of polyamine antagonism. Collectively, this work has built a growing body of evidence suggesting that the loss of surface GluR2 protein is an important contributing factor to neuronal dysfunction and cell death in excitotoxic CNS disease. To prevent the loss of surface GluR2, the intracellular mechanisms responsible for its aberrant endocytosis need to be mapped out, a problem that this study begins to address.

Interestingly, in this study, the reduction in surface GluR2 and subsequent AMPA receptor potentiation was NMDA receptor dependent. The simplest explanation is that the NMDAR dependence arises because of the structural link between PKC $\alpha$ and PSD-95. The -QSAV sequence on $P K C \alpha$ 's extreme c-terminus is a type I PDZ ligand with the potential to form a stable interaction with two of PSD-95's PDZ domains. ${ }^{23}$ However, our co-precipitation data do not rule out the possibility that PKC $\alpha$ is indirectly associated with PSD-95, through a binding partner that is able to bind both the kinase's PDZ ligand and one of PSD-95's PDZ domains.

We observed that $10 \mu \mathrm{M}$ NMDA did not result in the internalization or phosphorylation of GluR2 unless it was combined with stretch injury. Notably, we also observed that though stretch + NMDA on its own was not immediately cytotoxic, it imposed a marked vulnerability to secondary AMPA insult. There are a number of possibilities to explain the cooperative effects of stretch injury and NMDA on both AMPA receptor composition and neuronal susceptibility to secondary injury. Mechanical trauma reduces the magnesium block of the NMDA receptor ${ }^{24}$ potentially allowing an earlier innocuous dose of NMDA to initiate substantially more calcium influx in injured neurons versus controls. Indeed NMDA is markedly more lethal to stretched neurons than uninjured cultures ${ }^{19}$ and initiates larger calcium transients ${ }^{25}$ after sublethal stretch. These findings help in the understanding of how the two insults might cooperate in calcium-dependent PKC activation and GluR2 phosphorylation. In addition, mechanical trauma elevates intracellular superoxide levels in cortical neurons. ${ }^{19}$ Superoxide has an important function in PKC activation through thiol oxidation, ${ }^{26}$ including the regulation of kinase activity during $\mathrm{LTP}^{27,28}$ when PKC is active in the postsynaptic density and has a role in GluR2 removal. ${ }^{15}$ It is possible that oxidative modification causes preferential binding of PKC to various substrates, and we are currently investigating the hypothesis that superoxide is responsible for the post-injury PKCa-PSD95 association. In this scenario, PKCa - structurally connected to PSD-95 and embedded in the NMDAR protein complex after stretch - would be primed for activation from subsequent NMDAR stimulation.

It is important to also recognize the possibility that occupying the PDZ domains of PICK1 and/or PSD-95 with TAT-QSAV might be cytoprotective in a more non-specific manner than inhibiting PKC $\alpha$ binding. The PDZ domain of PICK1 interacts with at least 45 other known PDZ ligands. Occupying this domain with a -QSAV peptide could conceivably interfere with other PICK1 protein interactions. Further, there might conceivably exist other intracellular PDZ targets of the -QSAV sequence present on our peptide. Thus, though we show the successful perturbation of the PICK1-PKCa and PSD-95-PKCa association, we cannot definitively exclude the possibility that the cytoprotective effect of the compound is mediated elsewhere. Future work will include knocking down the expression of PKC $\alpha$ and/or PICK1 and investigating whether the cytoprotective effects of the peptide are occluded.

\section{Conclusions}

In modeled brain trauma at the cellular and pre-clinical levels, loss of surface GluR2 mediated by PICK1-PKC $\alpha$ activity contributes to progression of secondary injury and cell death. Accordingly, inhibiting the PDZ protein interactions that govern the trafficking of GluR2 represents a potential cytoprotective therapy aimed at preventing delayed excitotoxicity.

\section{Materials and Methods}

All procedures described here were approved by the Animal Care Committee at St. Michael's Hospital and complied with regulations of the Canadian Council on Animal Care.

Isolation and dissociation of cortical cell cultures. Cortical cultures containing both neurons and glia were prepared from E16-17 Wistar rats (Charles River Laboratories, Wilmington, MA, USA). Primary cultures were grown on 6-well BioFlex culture plates (FlexCell, Hillsborough, NC, USA). Pregnant animals were anesthetized with isofluorane and killed through decapitation. Embryos were surgically removed, isolated from the amniotic sac and decapitated. Embryo heads were placed in $20 \mathrm{ml} 1 \times$ Hank's Balanced Salt Solution (HBSS, Invitrogen Corp. Carlsbad, CA. USA). Brains were removed and placed in a separate dish containing $20 \mathrm{ml}$ supplemented HBSS. Cerebral cortices dissected from whole brains using microdissection forceps were incubated in $2 \mathrm{ml}$ of $0.1 \%$ trypsin (Sigma-Aldrich, St. Louis, MO, USA) at $37^{\circ} \mathrm{C}$ for $10 \mathrm{~min}$, and placed in $2 \mathrm{ml}$ HBSS. Tissue was triturated by glass pipette 10-20 times, and seeding medium (DMEM/F-12 containing $10 \%$ horse serum, Invitrogen) was added. Cortical cells were centrifuged for $5 \mathrm{~min}$ at 1200 r.p.m., triturated again, re-centrifuged at 700 r.p.m. for $1 \mathrm{~min}$ and seeded in plating medium (neurobasal medium containing 2\% B-27 supplement, $1 \%$ fetal bovine serum, $0.5 \mathrm{mM}$ L-glutamine, $25 \mu \mathrm{M}$ glutamic acid, Invitrogen) onto polyL-lysine ( $5 \mu \mathrm{g} / \mathrm{ml}$; Sigma)-coated plates at a density of $1 \times 10^{6}$ cells/well. Cell counts were carried out by loading PBS, Typan Blue (Sigma-Aldrich) and $50 \mu \mathrm{l}$ of cell suspension into a hemocytometer. Ninety-six hours after isolation, cells were fed with fresh maintenance medium (neurobasal medium containing $2 \%$ B-27 supplement, $0.5 \mathrm{mM}$ L-glutamine, Invitrogen) containing $10 \mu \mathrm{M}$ FDU $(5 \mathrm{mM}$ uridine, $5 \mathrm{mM}(+)-5$-fluor-2'-deoxyuridine, Invitrogen) and left to incubate for 
$48 \mathrm{~h}$ to halt the growth of non-neuronal cells. Cells were fed with maintenance medium every 3-4 days until stretch assays. We used the cells for experiments 1114 days after isolation consistent with earlier in vitro stretch assays. ${ }^{24,29,30}$

In vitro model of mild TBI. Before stretch, the culture medium was replaced with $2 \mathrm{ml}$ HEPES buffered saline (concentrations in $\mathrm{mM}: 121 \mathrm{NaCl}, 5 \mathrm{KCl}$, 20 glucose, 10 HEPES acid, 7 HEPES-Na salt, $3 \mathrm{NaHCO}_{3}, 1$ Na-pyruvate, 1.8 $\mathrm{CaCl}_{2}$ and 0.01 glycine, adjusted to $\mathrm{pH} 7.4$ with $\mathrm{NaOH}$ ). Cortical cell monolayer cultures were subjected to rapid stress-induced strain injury as established by ${ }^{31}$ using a Cell Injury Controller II (Custom Design and Fabrication, Virginia Commonwealth University, Richmond, VA, USA). This model has been validated earlier by our lab as a means to investigate intracellular mechanisms contributing to neuron death after strain injury. In brief, a controlled pulse of nitrogen gas induced a rapid deformation of the BioFlex's Silastic bottom resulting in a quantifiable biaxial stretch of the cortical cells adhered to the Silastic surface, without detachment of the cells. The system regulates the maximum pressure exerted on the plate bottom, minimizing the variation between trials. The duration of the stretch injury was set to $50 \mathrm{~ms}$ and the applied pressure levels ranged from $2.5-2.9$ pounds per square inch (p.s.i.), representative of mild rotational acceleration/deceleration injury resulting from rapid changes to angular velocity $(\omega)$, and subsequently, momentum $(L)$. According to the formula: impulse $(\mathcal{J}) \Delta P=F \Delta t$, (where $P=$ momentum, $F=$ force in newtons and $t=$ time $)$ and $F=$ pressure $(2.9$ p.s.i. $) \times$ area $\left(1.49 \mathrm{in}^{2}\right)$, we calculated that at 2.9 p.s.i., $J_{\text {(on cells) }} \approx 9.6 \mathrm{~N} \mathrm{~s}$. We have shown earlier that this sublethal trauma does not confer delayed cell death on its own - as assessed by propidium iodide uptake $20 \mathrm{~h}$ after injury - or alter membrane permeability, as assessed by carboxyfluorescein uptake and retention of fluorescein di-acetate. ${ }^{9}$ This model is highly consistent with other paradigms of in vitro TBI in the literature, ${ }^{30,32}$ which have frequently been used to delineate the intracellular mechanisms that contribute to progressive neuronal injury after mechanical trauma.

In the intact mammalian brain, tissue peripheral to the necrotic core of trauma undergoes not only mechanical strain, but is also subject to excitotoxic glutamatergic spillage ${ }^{33,34}$ from dead or dying neurons that are injured during the primary injury event. This post-trauma excitotoxic environment is largely lost in vitro, but may have an important function in progressive neuronal injury. Our intention with this model is to replicate in culture a similar or equivalent biomechanical loading and biochemical environment as found in in vivo TBI. Thus, immediately after the stretch, $10 \mu \mathrm{M}$ NMDA was added to the wells for $1 \mathrm{~h}$ to mimic this excitotoxic stimulation. Earlier studies of this dose of NMDA in cortical cultures have shown no lethality, and in fact promotion of neuroprotection against subsequent challenges. ${ }^{35}$ To block NR2b- and NR2a-containing NMDA receptors, respectively, $5 \mu \mathrm{M}$-[2-(4-hydroxyphenoxy)ethyl]-4-[(4-methylphenyl)methyl]-4-piperidinol (Co101244) hydrochloride and $\left(2 R^{*}, 4 S^{*}\right)-4-(3-p h o s p h o n o p r o p y l)-2$-piperidinecarboxylic acid (PPPA, $100 \mathrm{~nm}$ ) (Tocris Biosciences, Ellisville, MO, USA) were bath applied with NMDA. $K_{i}$ values of PPPA are 0.13 and $0.47 \mu \mathrm{m}$ for NR2A and NR2B, respectively, which ensured specificity of our approach.

Fluid percussion trauma. The FPI model has been extensively characterized in the rat model of TBI. ${ }^{36}$ In brief, male Wistar rats $(280-350 \mathrm{~g})$ were anesthetized with $2.0-2.5 \%$ halothane delivered in compressed air. Temperature was maintained by a thermal heating blanket at $37^{\circ} \mathrm{C}$. A craniotomy ( $\sim 2-3 \mathrm{~mm}$ diameter) was performed in the right lateral hemisphere, such that the medial edge of the craniotomy was approximately $2 \mathrm{~mm}$ from the midline suture, midway between bregma and lambda. A polyethylene tube was fixed to the opening with cyanoacrylate adhesive and dental acrylic, filled with $0.9 \%$ isotonic saline and attached to the FPI device. Rats were subject to a 2.0 atmosphere extradural fluid percussion impact. Bone wax was used to close the hole in the skull, and scalps were sutured before recovery in a temperature-controlled chamber. TAT peptides (dissolved in $\mathrm{ddH}_{2} \mathrm{O}$ ) were administered through intraperitoneal or intravenous injection at $1-3 \mathrm{mg} / \mathrm{kg}$ after closure of the head incision (i.e. approximately $10 \mathrm{~min}$ after the impact).

Protein extraction and quantification. After in vitro treatment, cells (an entire six-well plate, repeated three times, for a total of 18 wells per condition) were washed twice with ice-cold HEPES solution. Lysis buffer ( $250 \mu$ l per well) containing protease inhibitors ( $50 \mathrm{mM}$ Tris- $\mathrm{HCl}, 1 \% \mathrm{NP}-40,150 \mathrm{mM} \mathrm{NaCl}, 1 \mathrm{mM}$ EDTA, $1 \mathrm{mM}$ PMSF, $1 \mu \mathrm{g} / \mathrm{ml}$ aprotinin, $1 \mu \mathrm{g} / \mathrm{ml}$ leupeptin, $1 \mu \mathrm{g} / \mathrm{ml}$ pepstatin, $1 \mathrm{mM} \mathrm{NaF}$ ) was added and cell suspension was agitated at room temperature for $20 \mathrm{~min}$. Cell lysates were collected and centrifuged at $4^{\circ} \mathrm{C}(10000$ r.p.m.), and the pellet was discarded. Protein quantification was determined using the modified Lowry method. ${ }^{37}$ After quantification, aliquots of $500 \mu \mathrm{g}$ protein per condition were collected and frozen at $-80^{\circ} \mathrm{C}$ for subsequent immunoprecipitation for proteins of interest. Similar procedures were used in vivo, using homogenates of cortical tissue.

Co-immunoprecipitation. All immunoprecipitation procedures were performed at $4^{\circ} \mathrm{C}$ or on ice; $5 \mu \mathrm{g}$ of polyclonal rabbit anti-PICK1 (Abcam Inc., Cambridge, MA, USA) or $5 \mu \mathrm{g}$ of polyclonal rabbit anti-PSD-95 (Chemicon, Billerica, MA, USA) was incubated with $500 \mu \mathrm{g}$ of cell lysate and mixed by inversion overnight. Before being added to the antibody-lysate mixture, $50 \mu \mathrm{l}$ of protein $\mathrm{A}$ agarose beads were washed three times with $500 \mu \mathrm{l}$ of PBS (each time spun for $30 \mathrm{~s}$ at 10000 r.p.m.). After washing, protein $\mathrm{A}$ agarose beads were added to the antibody-lysis complex and incubated overnight to capture the antibody-antigen complex. As a negative control, we also incubated samples in the absence of primary anti-sera, with only protein A agarose. The antigen-antibody-bead complex was collected by pulse centrifugation (centrifuged at 14000 r.p.m. for $5 \mathrm{~s}$ ). The supernatant was discarded, and the beads were washed three times in icecold PBS. Bead complexes were then re-suspended in $60 \mu \mathrm{l} 2 \times$ sample buffer $(0.5 \mathrm{M}$ Tris- $\mathrm{HCl} \mathrm{pH} 6.8,20 \%$ glycerol, $10 \%$ SDS, $1 \%$ bromophenol blue, $5 \%$ $\beta$-mercaptoethanol), and boiled for $5 \mathrm{~min}$. The beads were pelleted by centrifugation, and SDS-PAGE was performed with the supernatant.

SDS-PAGE. For western blotting of whole-cell lysates, $20 \mu \mathrm{g}$ of boiled sample was loaded into each lane in $2 \times$ sample buffer. For electrophoresis of immunoprecipitated samples, $20 \mu \mathrm{l}$ supernatant was loaded per lane. For probing of phospho-serine880ct GluR2 and phospho-serine 845 GluR1, 7\% Tris/glycine gels were used, whereas a $12 \%$ gel was used to probe for PKC $\alpha$ after the immunoprecipitation of PICK1 and PSD-95. Protein samples were transferred onto nitrocellulose membranes for immunoblotting.

Immmunoblotting. After transfer, membranes were blocked in $5 \%$ blotting grade non-fat dry-milk (Bio-Rad, Hercules, CA, USA) in TBS-T (0.01 M Tris, $0.1 \mathrm{M}$ $\mathrm{NaCl}, 0.05 \%$ Tween 20 ) for $1 \mathrm{~h}$ at RT. To probe for phosho-serine880ct-GluR2, the immunogen (Chemicon, polyclonal, rabbit, 1:1000, diluted in $5 \%$ milk block) was a thyroglobulin-conjugated synthetic peptide corresponding to amino acids 873-883

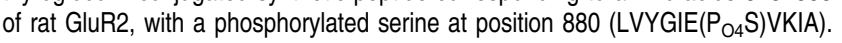
Immunoblotting for total GluR2 was performed with a polyclonal rabbit anti-GluR2 (1:1000, Chemicon) antibody. Phosphorylated GluR1 at serine 845 was detected using a polyclonal antibody to PS845 (Abcam, 1:400). After immunoprecipitation with PICK1, we probed for PKC $\alpha$ using a mouse, monoclonal anti-PKC $\alpha$ antibody (1:350, Upstate Biotechnology, Lake Placid, NY, USA). We sought to verify this interaction using both the aforementioned monoclonal antibody $(1: 350)$ and a separate rabbit anti-PKC $\alpha(1: 350$, Abcam) antibody. Hence, the immunoblots presented using the latter antibody contain a heavy chain IgG band at $55 \mathrm{kDa}$ (because both the immunoprecipitating and immunoblotting antibody were polyclonals hosted in rabbit), whereas the blots using the monoclonal $\mathrm{PKC} \alpha$ antibody do not contain the heavy chain IgG band. All primary antibodies were incubated overnight at $4^{\circ} \mathrm{C}$. After washing in TBS-T, HRP-conjugated goat antirabbit IgG $(1: 3000$, Chemicon) or HRP-conjugated goat anti-mouse $(1: 3000$, Chemicon) was added for $1 \mathrm{~h}$ at RT. We visualized immunoreactivty using an ECL western blotting detection kit (PerkinElmer, Wellesley, MA, USA). To verify equal protein loading in whole-cell blotting, membranes were re-probed with mouse anti- $\beta$ actin $(1: 2000$, Sigma), mouse anti-ERK $(1: 40000$, Sigma), and HRP-conjugated goat anti-mouse $(1: 3000)$. For immunoprecipitation, membranes were re-probed for the immunoprecipitating protein (PICK1, 1:500 or PSD-95, 1: 1000), and results were normalized to the amount of IP protein per lane. All immunoblotting and immunoprecipitation experiments were repeated in triplicate, with densitometry performed within the linear range of analysis. Densitometry analysis was performed using Gel-Pro Analyzer software (Media Cybernetics, San Diego, CA, USA). Integrated optical density of PKC $\alpha$ in both immunoprecipitation conditions was expressed as a ratio of PKC $\alpha / \mathrm{PICK} 1$ or PKC $\alpha / \mathrm{PSD}-95$. All results are normalized to control cultures, which are assumed to represent $100 \%$ expression.

Peptide synthesis and application. Inhibitory peptides were 15 amino acids in length, made up of the protein transduction domain of the HIV-1 TAT protein and the unique PKC $\alpha$ PDZ ligand QSAV (the PICK1-binding sequence), with a final sequence of Tyr-gly-arg-lys-lys-arg-arg-glu-arg-arg-arg-glu-ser-ala-val (Synthesized by CPC Scientific, San Jose CA, USA) Peptides were tagged with a dansyl chloride moiety for visualization of transduction. Control peptides (TATAAAA) had an alanine quadruplet in place of the QSAV sequence. Peptides were 
bath applied for $30 \mathrm{~min}$ at a concentration of $10 \mu \mathrm{M}$ in HEPES buffer to cortical cultures for all experiments in vitro. Cultures were washed thoroughly to remove untransduced peptide. Subsequently, sections of silastic membranes were cut, removed from the plate and placed in HEPES buffer. Live-cell fluorescence was visualized by fluorescence microscopy, and fixed cells were imaged using confocal microscopy. All parameters for image capture were kept constant among images (aperture, gain, black level, number of passes for Kallman integration). For confocal imaging, cells were fixed $30 \mathrm{~min}$ after peptide application, mounted on slides and imaged (see below for confocal imaging details). Unlabeled peptides were used for all experiments not involving visualization to eliminate the possible effects of the conjugate on the actions of the drug. Cells underwent stretch and NMDA application procedures $30 \mathrm{~min}$ after peptide application in these conditions.

Acid-strip immunofluorescence. To visualize the internalization of GluR2, $2 \mu \mathrm{g} / \mathrm{ml}$ monoclonal anti-GluR2 (Chemicon) recognizing the extracellular $\mathrm{N}$-terminus was bath applied to live cultures in medium. Cells were incubated at $37^{\circ} \mathrm{C}$ for $10 \mathrm{~min}$, and washed with warm HEPES-containing buffer to remove unbound antibody. Where appropriate, cells were then subjected to our model of injury. To examine the effect of blocking NR2b-containing NMDA receptors on AMPAR internalization, $5 \mu \mathrm{M}$ Co101244 hydrocholoride was bath applied with NMDA. After injury, cells were incubated for $1 \mathrm{~h}$ at $37^{\circ} \mathrm{C}$, and washed with ice-cold HEPES buffered saline to stop endocytosis. After the wash, cells underwent a 4 min acid strip using ice-cold solution of $0.2 \mathrm{M}$ acetic acid, and $0.5 \mathrm{M} \mathrm{NaCl}, \mathrm{pH} 2.8$. Cells were thoroughly washed in buffer again, and fixed for $15 \mathrm{~min}$ in $4 \%$ paraformaldehyde. After fixation, cells were permeabilized with $0.1 \%$ Triton- $X$ (or not permeabilized as a negative control), and anti-rabbit Alexa 488 secondary antibody was applied (1:1000, diluted in $4 \%$ NGS in PBS) for $1 \mathrm{~h}$ at RT. As a second negative control, live cells were fixed, permeabilized and incubated with anti-rabbit Alexa 488 secondary antibody alone (i.e. no primary antisera). To visualize fluorescence, images were acquired on a Leica DMIRE2 confocal microscope using a $\times 20$ objective, digitally magnified $\times 16$ on dendritic spines. Image capture settings were standardized for all images. A Z-series projection of 34 images at $0.5 \mu \mathrm{m}$ step intervals was used for each image capture and settings were always in the linear range of signal intensity.

To quantify dendritic immunofluorescent staining, we examined 1-2 distal dendrites per cell, which contained distinct protruding spines and did not exceed $50 \mu \mathrm{m}$ in length or $3 \mu \mathrm{m}$ in width of dendritic shaft. Using ImageProPlus software (Silver Spring, MD, USA) we calculated the area occupied by fluorescent puncta for each process, and divided this by the total area of the process. We collected data for 10 cells per condition per trial, and repeated this in triplicate across separate cultures. In each condition, cells were selected under bright field optics, and the investigator was blind to the treatment condition.

Spine sizes were quantified by measuring the diameter of the spine head (after fixation) using Image J. A line was manually drawn in image $J$ across the head of the spine, which was then converted from pixels to micrometers using the scale bars of the image. For the various types of dendritic spines, we measured the maximum diameter (i.e. the head of a mushroom and thin spine, the base of a stubby spine).

$\left[\mathrm{Ca}^{2+}\right]$ measurement. Cortical cells were incubated with $5 \mu \mathrm{M}$ Fura-PE3 AM (Teflabs, Austin, TX, USA) for $40 \mathrm{~min}$ at $37^{\circ} \mathrm{C}$, and then washed three times with HEPES buffered saline and left to incubate further for another $40 \mathrm{~min}$ to maximize dye hydrolysis. In our model of mild injury, neurons were incubated with the dye for $40 \mathrm{~min}$ along with $20 \mu \mathrm{M}$ naspm (Sigma) to selectively block GluR2-lacking AMPARs. Cells were washed, injured and allowed to incubate for $60 \mathrm{~min}$, to remain temporally consistent with previous assays. Circular selections of membranes ( 0.75 in diameter) were then removed from the well using a membrane sectioner, and perfused in HEPES buffer at room temperature. After collecting $150 \mathrm{~s}(30$ epochs of $5 s$ each) of stable baseline data, cells were perfused with HEPES containing $100 \mu \mathrm{M}$ AMPA and $50 \mu \mathrm{M}$ cyclothiazide (CTZ, for allosteric regulation of desensitization) for 45 epochs, and then returned to control HEPES. Cells were excited for $500 \mathrm{~ms}$ alternately at 340 and $380 \mathrm{~nm}$ at $5 \mathrm{~s}$ intervals, and an image from each excitation wavelength was captured using a high performance cooled $C C D$ camera (Sensicam, Cooke, Eugene, OR, USA). Volumetric flow rate of both HEPES buffer and AMPA + CTZ-containing buffer was $1.2 \mathrm{ml} / \mathrm{min}$. The emission intensity at $340 \mathrm{~nm}$ was divided by the intensity at $380 \mathrm{~nm}$, to calculate increases in cytosolic calcium. Figure 5 a provides a temporal schematic of our calcium imaging experiments.

To analyze regions of interest, cells were selected using Slidebook software (Intelligent Imaging Innovations Inc., Denver, CO, USA), with three parameters monitored by the experimenter: emission at $340 \mathrm{~nm}$, emission at $380 \mathrm{~nm}$ and the ratio of the two values. Calcium imaging was carried out in triplicate for control cells, and quadruplicate in the injury condition, across separate cell culture isolations. Calcium imaging of injury + naspm-treated cells was also repeated in triplicate. We quantified three data parameters: (i) the amount of time between peak emission and return to baseline; (ii) integration of the area under each calcium curve as an estimate of the relative quantity of excess cytosolic calcium; and (iii) compared values of peak emission during AMPA + CTZ perfusion (normalized to baseline ratios).

Secondary AMPA toxicity. Cortical cells underwent stretch alone, stretch + $10 \mu \mathrm{M}$ NMDA, or $10 \mu \mathrm{M}$ NMDA alone in $2 \mathrm{ml} \mathrm{HEPES}$ buffer as described above, and left to incubate for $1 \mathrm{~h}$ at $37^{\circ} \mathrm{C}$. Wells were subsequently loaded with $10 \mu \mathrm{g} / \mathrm{ml} \mathrm{PI}$ warmed in $37^{\circ} \mathrm{C}$ water bath. The quantitative measurements of $\mathrm{PI}$ fluorescence were used as a determination of the prevalence of cell death using a Victor ${ }^{3} \mathrm{~V}$ multi-well plate scanner (PerkinElmer) controlled by Workout software (Dazdaq, Finland). All parameters including the size and number of scanning area and the duration of scanning were kept constant by using the same protocol for all groups. One hour after stretch, $10 \mu \mathrm{M}$ NMDA, or the dual insult, baseline PI readings were taken. Cells were subsequently exposed to $30 \mu \mathrm{M}$ AMPA and further incubated at $37^{\circ} \mathrm{C}$ in the absence of $\mathrm{CO}_{2}$ for $1 \mathrm{~h}$. Cells were washed with buffer, and subsequent readings were taken $20 \mathrm{~h}$ later. Cell death in each condition was compared with unstretched wells exposed to $1 \mathrm{mM}$ glutamate (Glu) for $1 \mathrm{~h}$, which routinely produced a nearly $100 \%$ increase in cell death. Cell death was calculated according to the formula: \% increase in cell death $=F_{20} / F_{0}$, where $F_{20}=\mathrm{PI}$ fluorescence $20 \mathrm{~h}$ post insult and $F_{0}=$ initial PI fluorescence. Cell death was thus normalized to baseline readings. Cells exposed to $1 \mathrm{mM}$ Glu were identical cultures from the same dissection, in the same plate.

Whole-cell electrophysiology. Whole-cell patch-clamp recording was performed at room temperature in control neurons, as well as at $1 \mathrm{~h}$ after injury. The extracellular solution during recording was composed of (concentrations in mM): $128 \mathrm{NaCl}, 5 \mathrm{KCl}, 1.8 \mathrm{CaCl}_{2}, 1 \mathrm{Na}$-Pyruvate, $17 \mathrm{HEPES}$ acid, 20 D-glucose, $3 \mathrm{NaHCO}_{3}, 1 \mathrm{MgSO}_{4}, 0.001$ tetrodotoxin, 0.01 AP-5. Intracellular solution comprised (concentration in $\mathrm{mM}$ ) $128 \mathrm{CsOH}, 111$ gluconic acid, $4 \mathrm{NaOH}, 10 \mathrm{CsCl}$, $2 \mathrm{MgCl}, 10 \mathrm{HEPES}$ acid, $4 \mathrm{Na}_{2} \mathrm{ATP}, 0.4 \mathrm{Na}_{3} \mathrm{GTP}, 30$ sucrose, 0.1 1-Naspm, pH 7.3, $299 \mathrm{mOsm}$. Extracellular solution during sodium-free recordings consisted of: 128 choline chloride, $5 \mathrm{KCl}, 1.8 \mathrm{CaCl}_{2}$, $17 \mathrm{HEPES}$ acid, $20 \mathrm{D}$-Glucose, $1 \mathrm{MgSO}$. Holding potential was maintained at $-70 \mathrm{mV}$, and AMPAR-mediated mEPSCs were recorded and filtered at $2 \mathrm{kHz}$ using Clampex software (Axon Instruments, Union City, CA, USA). mEPSC amplitude was assayed using MiniAnalysis software (Synaptosoft, Decatur, GA, USA). Event threshold was set to $5 \mathrm{pA}$, and each mEPSC was analyzed individually. In examining the effects of $10 \mu \mathrm{M}$ TAT-QSAV and AAAA, neurons were treated post injury, and the peptide remained in the wells until recording.

Slice electrophysiology. All slice recordings were performed between 3 and $6 \mathrm{~h}$ after fluid percussion trauma. Stimulation $(0.1 \mathrm{~ms}$ in duration) was delivered using a bipolar tungsten electrode over a range of $40-90 \mu \mathrm{A}$ generated by a Grass S88 stimulator (Grass Instrument, West Warwick, RI, USA) and delivered through a PSIU6 isolation unit. Recording electrodes were pulled from filamented borosilicate glass capillary tubes with a P-97 Flaming/Brown micropipette (Sutter Instruments Co., Novato, CA, USA). Pipettes with resistances of 2-3M $\Omega$ were backfilled with $150 \mathrm{mM} \mathrm{NaCl}$. Signals were digitally recorded using an Axopatch 200B amplifier (Axon Instruments, Foster City, CA). All recordings were performed at room temperature and analyzed by pCLAMP software (Axon Instruments). Extracellular solution (perfused at a rate of $7 \mathrm{ml} / \mathrm{min}$ ) during all recordings consisted of (concentration in mM): $126 \mathrm{NaCl}, 3 \mathrm{KCl}, 1.4 \mathrm{KH}_{2} \mathrm{PO} 4,2.4 \mathrm{CaCl}_{2}, 1.3 \mathrm{MgSO}_{4}, 26$ $\mathrm{NaHCO}_{3}, 20$ glucose, and, when necessary, $0.02 \mathrm{Naspm}$, bubbled with carbogen $\left(95 \% \mathrm{O}_{2}, 5 \% \mathrm{CO}_{2}\right), 285 \pm 5 \mathrm{mOsm}$. One hour after FPI, animals were decapitated, and the brains were extracted in ice-cold aCSF. Recordings were performed on $450 \mu \mathrm{m}$ transverse hippocampal slices. Slices were acclimated to room temperature for a minimum of $60 \mathrm{~min}$ before recording. Recording electrodes were placed in the CA1 stratum pyramidale, with stimulation electrodes placed in the schaffer collateral tract. For sensitivity to the synthetic polyamine 1 -naspm, 5 min of perfusion with control aCSF was followed by a 7.5 min perfusion with aCSF $+20 \mu \mathrm{M}$ naspm. Slices were returned to control aCSF after naspm treatment.

Statistics. All data are representative of trials repeated at least three times across separate cell culture isolations unless otherwise indicated. Data are 
presented as mean \pm S.E.M. One-way ANOVAs with post hoc Tukey tests, or Dunn tests (in cases where tests of normality failed) were used to identify significant differences between treatment conditions in all assays.

Acknowledgements. We thank Elaine Liu for technical assistance with intravenous drug injections and Kevin Park for help with mathematical integration of calcium curves. We also thank Matthew Common for technical assistance. This work was supported by funding to AJB and JDB from the Ontario Neurotrauma Foundation and the Heart and Stroke Foundation of Ontario.

1. Park E, Bell JD, Baker AJ. Traumatic brain injury: can the consequences be stopped? CMAJ 2008; 178: 1163-1170.

2. Ikonomidou C, Turski L. Why did NMDA receptor antagonists fail clinical trials for stroke and traumatic brain injury? Lancet Neurol 2002; 1: 383-386.

3. Borges K, Dingledine R. AMPA receptors: molecular and functional diversity. Prog Brain Res 1998: 116: 153-170.

4. Kwak S, Weiss JH. Calcium-permeable AMPA channels in neurodegenerative disease and ischemia. Curr Opin Neurobiol 2006; 16: 281-287.

5. Isaac JT, Ashby M, McBain CJ. The role of the GluR2 subunit in AMPA receptor function and synaptic plasticity. Neuron 2007; 54: 859-871.

6. Liu B, Liao M, Mielke JG, Ning K, Chen $Y, L i ~ L$ et al. Ischemic insults direct glutamate receptor subunit 2-lacking AMPA receptors to synaptic sites. J Neurosci 2006; 26: 5309-5319.

7. Noh KM, Yokota H, Mashiko T, Castillo PE, Zukin RS, Bennett MV. Blockade of calciumpermeable AMPA receptors protects hippocampal neurons against global ischemiainduced death. Proc Natl Acad Sci USA 2005; 102: 12230-12235.

8. Rakhade SN, Zhou C, Aujla PK, Fishman R, Sucher NJ, Jensen FE. Early alterations of AMPA receptors mediate synaptic potentiation induced by neonatal seizures. J Neurosci 2008; 28: 7979-7990.

9. Bell JD, Ai J, Chen Y, Baker AJ. Mild in vitro trauma induces rapid Glur2 endocytosis, robustly augments calcium permeability and enhances susceptibility to secondary excitotoxic insult in cultured Purkinje cells. Brain 2007; 130: 2528-2542.

10. Spaethling JM, Klein DM, Singh P, Meaney DF. Calcium-permeable AMPA receptors appear in cortical neurons after traumatic mechanical injury and contribute to neuronal fate. J Neurotrauma 2008; 25: 1207-1216.

11. Perez JL, Khatri L, Chang C, Srivastava S, Osten P, Ziff EB. PICK1 targets activated protein kinase Calpha to AMPA receptor clusters in spines of hippocampal neurons and reduces surface levels of the AMPA-type glutamate receptor subunit 2. J Neurosci 2001; 21: $5417-5428$.

12. Chung HJ, Xia J, Scannevin RH, Zhang X, Huganir RL. Phosphorylation of the AMPA receptor subunit GluR2 differentially regulates its interaction with PDZ domain-containing proteins. J Neurosci 2000; 20: 7258-7267.

13. Leitges M, Kovac J, Plomann M, Linden DJ. A unique PDZ ligand in PKCalpha confers induction of cerebellar long-term synaptic depression. Neuron 2004; 44: 585-594.

14. Terashima A, Cotton L, Dev KK, Meyer G, Zaman S, Duprat F et al. Regulation of synaptic strength and AMPA receptor subunit composition by PICK1. J Neurosci 2004; 24: 5381-5390.

15. Terashima A, Pelkey KA, Rah JC, Suh YH, Roche KW, Collingridge GL et al. An essential role for PICK1 in NMDA receptor-dependent bidirectional synaptic plasticity. Neuron 2008; 57: 872-882.

16. Seidenman KJ, Steinberg JP, Huganir R, Malinow R. Glutamate receptor subunit 2 Serine 880 phosphorylation modulates synaptic transmission and mediates plasticity in CA1 pyramidal cells. J Neurosci 2003; 23: 9220-9228.
17. Chung HJ, Steinberg JP, Huganir RL, Linden DJ. Requirement of AMPA receptor GluR2 phosphorylation for cerebellar long-term depression. Science 2003; 300: 1751-1755.

18. Saglietti L, Dequidt C, Kamieniarz K, Rousset MC, Valnegri $P$, Thoumine $O$ et al. Extracellular interactions between GluR2 and N-cadherin in spine regulation. Neuron 2007; 54: 461-477.

19. Arundine M, Aarts M, Lau A, Tymianski M. Vulnerability of central neurons to secondary insults after in vitro mechanical stretch. J Neurosci 2004; 24: 8106-8123.

20. Serulle $Y$, Zhang S, Ninan I, Puzzo D, McCarthy M, Khatri L et al. A GluR1-cGKII interaction regulates AMPA receptor trafficking. Neuron 2007; 56: 670-688.

21. Santos AE, Duarte CB, lizuka M, Barsoumian EL, Ham J, Lopes MC et al. Excitotoxicity mediated by Ca2t-permeable GluR4-containing AMPA receptors involves the AP-1 transcription factor. Cell Death Differ 2006; 13: 652-660.

22. Lu YM, Yin HZ, Chiang J, Weiss JH. Ca(2+)-permeable AMPA/kainate and NMDA channels: high rate of $\mathrm{Ca} 2+$ influx underlies potent induction of injury. J Neurosci 1996; 16 : 5457-5465.

23. Lim IA, Hall DD, Hell JW. Selectivity and promiscuity of the first and second PDZ domains of PSD-95 and synapse-associated protein 102. J Biol Chem 2002; 277: $21697-21711$.

24. Zhang L, Rzigalinski BA, Ellis EF, Satin LS. Reduction of voltage-dependent Mg2+ blockade of NMDA current in mechanically injured neurons. Science 1996; 274: 1921-1923.

25. Geddes-Klein DM, Schiffman KB, Meaney DF. Mechanisms and consequences of neuronal stretch injury in vitro differ with the model of trauma. J Neurotrauma 2006; 23: 193-204.

26. Knapp LT, Klann E. Superoxide-induced stimulation of protein kinase $C$ via thiol modification and modulation of zinc content. J Biol Chem 2000; 275: 24136-24145.

27. Knapp LT, Klann E. Potentiation of hippocampal synaptic transmission by superoxide requires the oxidative activation of protein kinase C. J Neurosci 2002; 22: 674-683.

28. Knapp LT, Klann E. Role of reactive oxygen species in hippocampal long-term potentiation: contributory or inhibitory? J Neurosci Res 2002; 70: 1-7.

29. Goforth PB, Ellis EF, Satin LS. Enhancement of AMPA-mediated current after traumatic injury in cortical neurons. J Neurosci 1999; 19: 7367-7374.

30. Lau A, Arundine M, Sun HS, Jones M, Tymianski M. Inhibition of caspasemediated apoptosis by peroxynitrite in traumatic brain injury. J Neurosci 2006; 26: 11540-11553.

31. Ellis EF, McKinney JS, Willoughby KA, Liang S, Povlishock JT. A new model for rapid stretch-induced injury of cells in culture: characterization of the model using astrocytes. J Neurotrauma 1995; 12: 325-339.

32. Engel DC, Slemmer JE, Vlug AS, Maas AI, Weber JT. Combined effects of mechanical and ischemic injury to cortical cells: secondary ischemia increases damage and decreases effects of neuroprotective agents. Neuropharmacology 2005; 49: 985-995.

33. Nilsson P, Hillered L, Ponten U, Ungerstedt U. Changes in cortical extracellular levels of energy-related metabolites and amino acids following concussive brain injury in rats. J Cereb Blood Flow Metab 1990; 10: 631-637.

34. Rose ME, Huerbin MB, Melick J, Marion DW, Palmer AM, Schiding JK et al. Regulation of interstitial excitatory amino acid concentrations after cortical contusion injury. Brain Res 2002; 943: 15-22

35. Soriano FX, Papadia S, Hofmann F, Hardingham NR, Bading H, Hardingham GE. Preconditioning doses of NMDA promote neuroprotection by enhancing neuronal excitability. J Neurosci 2006; 26: 4509-4518.

36. Dixon CE, Lyeth BG, Povlishock JT, Findling RL, Hamm RJ, Marmarou A et al. A fluid percussion model of experimental brain injury in the rat. J Neurosurg 1987; 67 : 110-119.

37. Peterson GL. A simplification of the protein assay method of Lowry et al. which is more generally applicable. Anal Biochem 1977; 83: 346-356. 